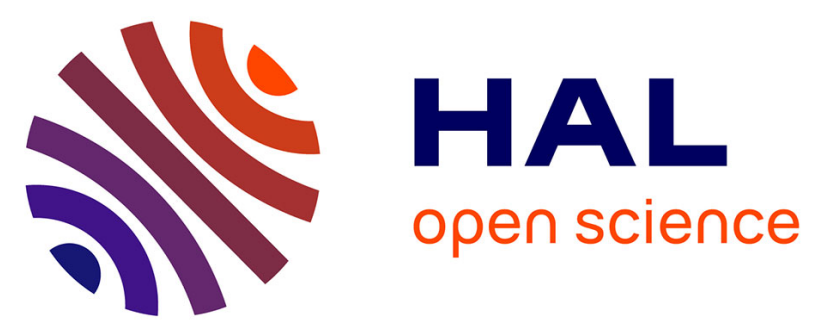

\title{
A single-shot Lassa vaccine induces long-term immunity and protects cynomolgus monkeys against heterologous strains
}

\author{
Mathieu Mateo, Stéphanie Reynard, Alexandra Journeaux, Clara Germain, \\ Jimmy Hortion, Xavier Carnec, Caroline Picard, Nicolas Baillet, Virginie \\ Borges-Cardoso, Othmann Merabet, et al.
}

\section{To cite this version:}

Mathieu Mateo, Stéphanie Reynard, Alexandra Journeaux, Clara Germain, Jimmy Hortion, et al.. A single-shot Lassa vaccine induces long-term immunity and protects cynomolgus monkeys against heterologous strains. Science Translational Medicine, 2021, 13 (597), pp.eabf6348. 10.1126/scitranslmed.abf6348 . pasteur-03256146

\section{HAL Id: pasteur-03256146 \\ https://hal-pasteur.archives-ouvertes.fr/pasteur-03256146}

Submitted on 10 Jun 2021

HAL is a multi-disciplinary open access archive for the deposit and dissemination of scientific research documents, whether they are published or not. The documents may come from teaching and research institutions in France or abroad, or from public or private research centers.
L'archive ouverte pluridisciplinaire HAL, est destinée au dépôt et à la diffusion de documents scientifiques de niveau recherche, publiés ou non, émanant des établissements d'enseignement et de recherche français ou étrangers, des laboratoires publics ou privés.

\section{(ㄷ)(1) $\$$}

Distributed under a Creative Commons Attribution - NonCommerciall 4.0 International 


\section{A single-shot Lassa vaccine induces long-term immunity and protects cynomolgus monkeys against heterologous strains}

Mathieu Mateo ${ }^{1,2}$, Stéphanie Reynard ${ }^{1,2}$, Alexandra Journeaux ${ }^{1,2}$, Clara Germain ${ }^{1,2}$, Jimmy Hortion ${ }^{1,2}$, Xavier Carnec ${ }^{1,2}$, Caroline Picard ${ }^{1,2}$, Nicolas Baillet ${ }^{1,2}$, Virginie Borges-Cardoso ${ }^{1,2}$, Othmann Merabet1,2, Audrey Vallve ${ }^{3}$, Stéphane Barron ${ }^{3}$, Ophélie Jourjon ${ }^{3}$, Orianne Lacroix ${ }^{3}$, Aurélie Duthey33, Manon Dirheimer4 ${ }^{4}$ Gregory Jouvion ${ }^{5,6}$, Pierre-Henri Moreau ${ }^{7}$, Lyne Fellmann ${ }^{7}$, Caroline Carbonnelle $^{3}$, Hervé Raoul ${ }^{3}$, Frédéric Tangy ${ }^{8}$, and Sylvain Baize ${ }^{1,2,+}$

${ }^{1}$ Unité de Biologie des Infections Virales Emergentes, Institut Pasteur, 69007, Lyon, France

${ }^{2}$ Centre International de Recherche en Infectiologie (CIRI), Université de Lyon, INSERM U1111, Ecole Normale Supérieure de Lyon, Université Lyon 1, CNRS UMR5308, 69007, Lyon, France

${ }^{3}$ Laboratoire P4 INSERM - Jean Mérieux, INSERM US003, 69007, Lyon, France

${ }^{4}$ INSERM, Délégation Régionale Auvergne Rhône-Alpes, 69500, Bron, France

${ }^{5}$ Ecole Nationale Vétérinaire d'Alfort, Unité d'Histologie et d'Anatomie pathologique, 94700, Maisons-Alfort, France

${ }^{6}$ Dynamic Research Group, Université Paris Est Créteil, Ecole Nationale Vétérinaire d'Alfort, USC ANSES, 94700, Maisons-Alfort, France

${ }^{7}$ SILABE, Université de Strasbourg, fort Foch, 67207, Niederhausbergen, France

${ }^{8}$ Viral Genomics and Vaccination, Institut Pasteur, CNRS UMR-3569, 75015, Paris, France

+Corresponding author. sylvain.baize@pasteur.fr (S.B.) 


\begin{abstract}
A safe and protective Lassa virus vaccine is crucially needed in Western Africa to stem the recurrent outbreaks of Lassa virus infections in Nigeria and the emergence of Lassa virus in previously unaffected countries, such as Benin and Togo. Major challenges in developing a Lassa virus vaccine include the high diversity of circulating strains and their re-emergence from one year to another. To address each of these challenges, we immunized cynomolgus monkeys with a measles virus vector expressing the Lassa virus glycoprotein and nucleoprotein of the prototypic Lassa virus strain Josiah (MeV-NP). To evaluate vaccine efficacy against heterologous strains of Lassa virus, we challenged the monkeys a month later with heterologous strains from lineage II or lineage VII, finding that the vaccine was protective against these strains. A second cohort of monkeys was challenged one year later with the homologous Josiah strain, finding that a single dose of MeVNP was sufficient to protect all vaccinated monkeys. These studies demonstrate that MeV-NP can generate both long-lasting immune responses and responses that are able to protect against diverse strains of Lassa virus.
\end{abstract}

\title{
ONE SENTENCE SUMMARY
}

A single dose vaccine confers cross-protection and long-term efficacy against Lassa virus in cynomolgus monkeys. 


\section{INTRODUCTION}

Lassa virus (LASV) is endemic to West Africa, where it circulates in rodents, of which Mastomys natalensis is the main natural reservoir. Rodent-to-human transmission accounts for most human cases and often occurs during the dry season, when the rodent population peaks and comes into closer proximity to human populations to find resources $(1,2)$. Most infections follow mucosal contact with food or dust contaminated with rodent excrements. Human-to-human transmission is rare and mostly nosocomial after contact with infected fluids. Although most infected individuals survive a LASV infection, 15 to $50 \%$ of hospitalized patients die from Lassa fever. Severe complications may appear after recovery, with up to one-third of survivors developing a hearing deficit that can be irreversible (3). Lassa fever thus constitutes a major health problem in endemic areas and, in the absence of an effective treatment or vaccine, the World Health Organization (WHO) recently placed Lassa fever in the top priority list of viral diseases for which a vaccine is urgently needed.

With up to 180 million people at risk for Lassa fever (4), mass vaccination would indeed reduce the risk of major Lassa fever epidemics in both endemic or currently unaffected countries. To achieve this goal, the Coalition for Epidemics Preparedness Innovations (CEPI) has initiated a global program to develop vaccines against emerging infectious diseases and promote equitable access to vaccination for all during outbreaks, including substantial support of the development of a LASV vaccine from preclinical to clinical phases. The development of a LASV vaccine faces several challenges and the WHO has published a Target Product Profile (TPP) that defines the characteristics of an appropriate LASV vaccine. A preventive vaccine is preferred over a reactive vaccine, and the vaccine should be safe for all age groups, preferentially provide protection after a single immunization, induce long-term protection to cover several Lassa fever seasons, and cross-protect against several LASV lineages (5).

Cross-protection is likely the most challenging aspect of the TPP. A recent metagenomics analyses of the LASV strains recovered from patients during the recent 2018 outbreak in Nigeria revealed a high diversity of genetically distinct co-circulating strains belonging to several different lineages (2). There are currently seven known lineages of LASV strains established based on their 
genetic diversity $(6,7)$. Lineages I, II, and III include strains circulating in Nigeria (8). Lineage IV is represented by strains originating from Guinea, Sierra Leone, and Liberia (9). This includes the prototypic Josiah strain, isolated from a Sierra Leonean patient in 1976. Lineage $V$ comprises strains from Mali and Côte d'Ivoire. Strains from lineage VI were isolated in Hylomyscus pamfi from Nigeria (6). Finally, lineage VII is represented by strains that emerged in Togo and Benin during the epidemics of 2014 and 2016 (7). Although the distribution of each of the seven lineages appears to be restricted to specific geographic locations, the introduction of LASV from one country to another can occur $(7,10)$ and may become more frequent with the rapid development of West Africa. In addition, LASV is the most frequently exported hemorrhagic fever virus, in most cases by healthcare workers returning to their home countries after contracting the disease $(11,12)$. Although the WHO TPP indicates that vaccination should protect against lineages I to IV, conferring protection against all lineages would be preferred. However, the high diversity of LASV strains implies that vaccine development would have to address certain antigenic issues. The two major LASV antigens, the glycoprotein (GPC) and the nucleoprotein (NP), diverge considerably between lineages, with up to $15 \%$ dissimilarity between two NP proteins (8). This may be problematic, as all LASV vaccines in development are based on the antigens from lineage IV (13). In addition, GPC is often used as the sole antigen in vaccine candidates, whereas immune responses against NP, notably T cell responses, have been shown to be crucial for the recovery of LASV survivors (14-16) and the protection of vaccinated monkeys $(10,13)$.

Among the LASV vaccine candidates that have been developed over the past decades (5), several have shown promising results in preclinical studies and have therefore received support from the CEPI for further development. Vesiculovax, a modified recombinant vesicular stomatitis virus (VSV) that expresses LASV GPC, was shown to protect monkeys from a lethal challenge with a heterologous strain from lineage II when administered twice, along with a filovirus vaccine (17). Another VSV-based vaccine, rVSVDG-LASV-GPC, also protected guinea pigs against lineage I and IV strains and monkeys against two strains from lineage IV after a single immunization (18, 19). A DNA vaccine, pLASV-GPC, also protects monkeys after three intradermal injections (20). Importantly, none of these three vaccines have demonstrated long-term efficacy in monkeys in preclinical studies. 
We have previously developed MeV-NP, a recombinant measles virus vaccine that expresses LASV GPC and NP, both from the Josiah strain. In this vaccine, the gene encoding NP was further modified to abolish its ability to dampen the immunogenicity of the measles backbone (21). We have previously demonstrated that a single immunization with MeV-NP protects monkeys against a lethal challenge with the homologous Josiah strain, and that protection was mostly linked to the elicitation of T cell responses against GPC and NP (10). MeV-NP was also selected by the CEPI and is currently undergoing a first-in-human phase I clinical trial (NCT04055454) under the name MV-LASV. MeV-NP has specific characteristics that could make it an appropriate vaccine against LASV. The measles platform is safe and is currently being used in several clinical trials for other viral diseases (22-25). Measles vaccination confers life-long immunity and measles-based vectors may also induce long-term immunity against the targeted pathogens. MeV-NP, like other measles virus-based vaccines, induces anti-measles antibodies (10) and could therefore immunize against two pathogens in naïve recipients or boost the immune response towards measles in seroconverted individuals, as pre-existing immunity does not seem to affect its immunogenic properties (23). It is yet to be determined whether a single immunization with MeV-NP can crossprotect against divergent strains of LASV and induce long-term protection against infection against the homologous strain of LASV.

Here, we tested whether a single dose of MeV-NP can protect monkeys against divergent strains from lineage II, generally responsible for the yearly Lassa fever burden $(2,26)$, and lineage VII, a recently emerged lineage that has shown an unusually high case fatality rate of $50 \%$ in Togo and Benin and that shows the highest divergence from lineage IV strains (7). We also assessed whether MeV-NP can induce long-term protection in monkeys challenged over one year postvaccination and whether a prime-boost regimen could be beneficial for such protection. 


\section{RESULTS}

\section{Immunization of cynomolgus monkeys}

In total, 23 monkeys were used to assess the cross-protection and long-term efficacy of MeV-NP. For evaluation of cross-protection, four groups of three monkeys were immunized by the subcutaneous (SC) route with $2 \times 10^{6}$ tissue-culture infective doses ( $\left.\mathrm{TCI}_{50}\right)$ of MeV-NP or MeV as a negative control (Fig. 1A). Monkeys in the MeV groups were vaccinated with the measles virus Schwarz strain vaccine. Groups were characterized based on vaccination with MeV-NP (V) or control vaccination $(C)$ and challenge with either the Lineage VII Benin strain (B) or the Lineage II Nigeria strain (N), leading to four groups: VB (orange), CB (blue), VN (red), and CN (gray).

For evaluation of long-term protection, one group of four monkeys was immunized one time by the intramuscular (IM) route with $2 \times 10^{6} \mathrm{TCID}_{50}$ of MeV-NP for subsequent challenge with the Josiah strain of LASV (group VJ-P, red, Fig. 1B). Another group of four received prime and boost (PB) IM immunizations with $2 \times 10^{5} \mathrm{TCID}_{50}$ of MeV-NP spaced one month apart prior to challenge with the Josiah strain of LASV (group VJ-PB, blue, Fig. 1B). An additional control group of three monkeys was immunized by two IM injections of $2 \times 10^{5} \mathrm{TCID}_{50}$ of $\mathrm{MeV}$ spaced one month apart for subsequent challenge with the Josiah strain of LASV (group CJ, grey, Fig. 1B). Monkeys were immunized through the IM route to confirm that SC or IM routes does not affect the immunogenicity of the vaccine, as shown for the MMRV vaccine in clinical trials (27) and to match the immunization route used in the clinical trial. After immunization, no alteration of the biological parameters, including body temperature, weight, and respiratory rate, of any monkey was observed during the time between immunization and challenge, which was 37 days for the VN, $C N, V B$ and $C B$ monkeys and 383 days for the VJ-P and VJ-PB monkeys (Fig. 1A and B). We assessed potential viremia due to the vaccine for several days following each immunization by reverse transcriptase polymerase chain reaction (RT-PCR) and detected no vaccine replication in peripheral blood mononuclear cells or plasma, nor shedding in the oral or nasal excretions or urine (tables S1 and S2), as reported previously (10), reinforcing the apparent safety of MeV-NP.

\section{Antibody responses are induced after MeV-NP immunization}


We measured the induction of LASV-specific immunoglobulin $M(\lg M)$ and $G(\lg G)$ after immunization using whole LASV antigens. Two out of the three monkeys in the VB and VN groups showed detectable IgM activity against the whole antigens of the homologous LASV lineage IV at day 14 at a low dilution, whereas no IgM was detected for the CB or VB groups (Fig. 2A, upper panel). We also assessed the presence of IgM directed against heterologous lineage II and VII in these monkeys and only detected a low titer of IgM directed against lineage VII in one VB monkey (Fig. 2A, center panel). No monkeys developed IgM responses against lineage II (Fig. 2A, bottom panel).

During the immunization period, all monkeys in the VB and VN groups developed an IgG response against the whole antigens of the homologous lineage IV between days 14 and 37 (Fig. 2B, upper panel) and the three monkeys in the VB group also produced heterologous LASVspecific IgG with the same kinetics (Fig. 2B, center panel). However, no lineage II-specific IgG were detected in VN monkeys (Fig. 2B, lower panel). To improve the sensitivity of detection and determine the respective contribution of LASV NP and GP in the humoral responses, we also used recombinant antigens. VB and VN monkeys all produced IgG recognizing NP lineage IV by day 14 or 25 (Fig. 2C, upper panel) and cross-reacting with NP lineage II at day 25 (Fig. 2D, upper panel). IgG recognizing GP lineage IV at day 25 (Fig. 2C, lower panel) were detected in one monkey from each VB and VN groups. IgG of two VB monkeys and one CN also cross-reacted with GP lineage II at day 25 (Fig. 2D, lower panel).

Two out of the three monkeys in the VJ-P and VJ-PB groups produced homologous LASVspecific IgM by day 16, and one monkey in the VJ-P group still exhibited a low titer at day 35 (Fig. 2E). None of the three CJ controls developed LASV-specific IgM (Fig. 2E). Homologous LASVspecific IgG against GP and NP also appeared in all monkeys in the VJ-P and VJ-PB groups between days 16 and 35 and were detected up to 317 days post-immunization (DPI) (Fig. 2F). Concentrations of anti-GP (Fig. 2F, left panel) and anti-NP (Fig. 2F, center panel) IgG were similar between the VJ-P and VJ-PB monkeys. The concentrations of IgG against LASV Josiah were significantly higher for the VJ-PB than VJ-P monkeys between 44 and $163 \mathrm{DPI}(P=0.0286$, Fig. 2F, right panel).

\section{T cell responses induced after immunization}


LASV-specific T cells from whole blood were analyzed after immunization by quantifying the $\mathrm{CD}^{+}$and $\mathrm{CD}^{+}{ }^{+} \mathrm{T}$ cells producing interferon (IFN)- $\gamma$ or tumor necrosis factor- $\alpha$ (TNF- $\alpha$ ) after stimulation with overlapping peptides covering all of LASV GPC and NP. A low number of T cells produced cytokines 14 or 25 DPI during the cross-protection experiment (Fig. 3A and B). A low but statistically significant production was observed by $\mathrm{CD}^{+} \mathrm{T}$ cells in response to Josiah or Benin LASV GPC peptides at days 14 and 25, respectively ( $P=0.037$ and 0.048 , respectively, Fig. 3A). Otherwise, the production of cytokines in response to the various LASV strains was variable, except for $\mathrm{CD}^{+} \mathrm{T}$ cells at day 25, when a similar percentage of cytokine-producing cells was observed in response to Josiah-, Benin-, or Nigeria-derived GPC and NP peptides (Fig. 3B). The LASV-specific T cells produced mainly TNF- $\alpha$ only, but a proportion of T cells expressed both TNF- $\alpha$ and IFN- $\gamma$ or IFN- $\gamma$ alone, primarily in response to Josiah and Benin GPC peptides (Fig. 3C).

When we isolated samples from monkeys in the long-term vaccination experiment, we found that the peak of the T cell response occurred 35 DPI for VJ-P monkeys, with 0.3 to $0.5 \%$ of $\mathrm{CD}^{+}$and $\mathrm{CD}^{+}{ }^{+}$cells producing cytokines in response to GPC and NP peptides from LASV Josiah and $A V$, a strain representative of lineage $V(28)$ (Fig. 3D and $E$ ), with a significant difference as compared to CJ monkeys for NP-specific CD8 ${ }^{+} \mathrm{T}$ cells $(P=0.046$ and 0.012 , respectively, Fig. 3E, upper left panel). We also observed significant differences as compared to CJ monkeys for CD8 ${ }^{+}$ responses against Josiah NP peptide stimulation at day $23(P=0.007)$ and for $\mathrm{CD}^{+} \mathrm{T}$ cell responses following AV NP peptide stimulation at days $16(P=0.002)$ (Fig. 3E, left panels). The peak $\mathrm{T}$ cell responses in prime-boost monkeys were measured at day 42 , or seven days after the boost, with 0.2 to $0.5 \%$ of $\mathrm{CD}^{+}$and $\mathrm{CD} 4^{+} \mathrm{T}$ cells producing cytokines in response to Josiah and AV GPC and NP peptides (Fig. 3D and E). We observed a statistically significant difference between VJ-PB vaccinated and CJ monkeys for the Josiah GPC-specific CD8 ${ }^{+} \mathrm{T}$ cells and for the AV GPC-specific CD4 ${ }^{+}$T cells $(P=0.023$ and 0.041 , respectively, Fig. 3D, right panels). A large proportion of AV NPspecific cytokine-producing $\mathrm{CD}^{+} \mathrm{T}$ cells were also observed 16 and 35 days after the prime immunization as compared to $C J$ monkeys $(P=0.015$ and 0.021 , respectively, Fig. $3 \mathrm{E}$, upper right panel). Again, TNF- $\alpha$ was the main cytokine detected at the peak of the response, but a small proportion of T cells from prime-only monkeys produced both TNF- $\alpha$ and IFN- $\gamma$ in response to NP 
(Fig. 3F). The T cell responses were more diversified at $140 \mathrm{DPI}$, with the appearance of both TNF$\alpha^{+}$IFN- $\gamma^{+}$and TNF- $\alpha^{-}$IFN- $\gamma^{+}$T cells, except for Josiah GPC peptides and CD4 ${ }^{+}$T cells (Fig. 3F).

Memory $\mathrm{T}$ cell responses were also analyzed in peripheral blood mononuclear cells (PBMCs) collected at 317 days post immunization by stimulating cells with Josiah GPC- or NPderived peptides and analyzing the expression of activation molecules four days after (Fig. 3G to I). A higher percentage of $C D 8^{+} T$ cells from VJ-P and VJ-PB monkeys expressed Granzyme B (GrzB) and perforin (Perf) in response to GPC peptides (Fig. 3G, left panel) and from VJ-PB monkeys compared to $\mathrm{CD}^{+} \mathrm{T}$ cells from CJ monkeys in response to NP peptides (Fig. 3G, right panel). A higher percentage of $\mathrm{CD}^{+}$and $\mathrm{CD}^{+} \mathrm{T}$ cells expressing the $\mathrm{T}$ cell costimulation molecule CD137 (29) in response to NP were also detected in PBMCs from VJ-P and VJ-PB monkeys at 317 days post immunization compared to T cells from CJ monkeys (Fig. $3 \mathrm{H}$ ) and a higher proportion of CD4 ${ }^{+}$

T cells from vaccinated monkeys expressed human leukocyte antigen (HLA)-DR in response to both GPC and NP compared to CD4 ${ }^{+} \mathrm{T}$ cells from CJ monkeys (Fig. 3l).

\section{A single shot of MeV-NP protects monkeys against heterologous strains and induces long- term protection}

At the end of the immunization phase, three control (CB) and three immunized monkeys (VB) were challenged with a SC injection of 3,000 focus-forming units (FFU) of the heterologous LASV Benin strain (lineage VII) (table S3). In addition, three control (CN) and three immunized monkeys (VN) were challenged by the same route with 3,000 FFU of the heterologous Nigeria LASV strain (lineage II) (table S3). Three control (CJ), four prime-only immunized (VJ-P), and four prime-boost immunized monkeys (VJ-PB) received 1,500 FFU of LASV Josiah (lineage IV) by the SC route. The monkeys were then monitored for up to 30 days and attributed clinical scores based on their body temperature, weight, food and water intake, behavior, and clinical signs, with a score of 15 being the endpoint for euthanasia.

The clinical scores of the three CB controls showed an increase by day 6 and they were euthanized before day 15, whereas all VB monkeys survived the infection (Fig. 4A, left panels). The CB controls showed signs of aggressiveness and stress by day 4 post-challenge, and their tonus was lower by day 7, accompanied by dehydration. Their body temperature started to increase by day 3 and remained elevated until day 9, before decreasing for all monkeys until the time of 
euthanasia (Fig. 4B). By day 12, CB-2 and CB-3 were asthenic and started shivering, and CB-1 had to be euthanized due to a body temperature below $35^{\circ} \mathrm{C}$, which represents a mandatory endpoint (Fig. 4A, upper left panel, pink line). CB-3 was euthanized on day 14 for the same reason (Fig. 4A, upper left panel, light blue line), whereas CB-2 was euthanized on day 15 with a severe hypothermia below $32^{\circ} \mathrm{C}$ (Fig. $4 \mathrm{~A}$ and $\mathrm{B}$, upper left panel, dark blue line). In contrast, VB monkeys had consistently low clinical scores that reached their highest point around day 9 (Fig. 4A, lower left panel). They did not show dramatic changes in body temperature (Fig. 4B, lower left panel) but showed less tonus and were moderately dehydrated between days 8 and 10 .

The three $\mathrm{CN}$ controls also showed signs of stress, dehydration, and asthenia during the first nine days but then presented different clinical pictures (Fig. 4A, upper right panel). The clinical score of $\mathrm{CN}-1$ (pink line) rapidly increased from day 9, when its body temperature reached a maximum (Fig. 4B, upper right panel, pink line), and was euthanized at day 12 after two days with a continuous nosebleed and severe diarrhea. The clinical score of $\mathrm{CN}-3$ (Fig. 4A, upper right panel, light blue line) also increased rapidly from day 9 to day 12, but it survived to day 20 and was euthanized after showing severe balance problems for two consecutive days. The peak in the clinical score coincided with a peak in body temperature at day 9 (Fig. 4B, upper right panel, light blue line). The clinical score of $\mathrm{CN}-2$ (Fig. 4A, upper right panel, dark blue line) increased more slowly up to day 15 , reaching a score of 8 , but then remained stable for a week and decreased thereafter. This monkey survived the infection without any measurable fever (Fig. 4B, upper right panel, dark blue line) and was euthanized at the end of the protocol with a score of 5. By contrast, none of the VN monkeys developed any signs of disease. They all survived the infection, with clinical scores remaining below 3 (Fig. 4A, lower right panel) and without showing evidence of hyperthermia (Fig. 4B, lower left panel). MeV-NP therefore protects monkeys against heterologous LASV strains from lineage II and lineage VII after a single immunization.

For monkeys infected to assess long-term vaccine-mediated protection, we also evaluated clinical score and body temperature. The three CJ controls were euthanized between days 12 and 14 (Fig. 4C, upper panel) and all presented clinical signs of Lassa fever including diarrhea, dehydration, and low tonus, as well as a high body temperature between days 6 and 12 (Fig. 4D, upper panel). Between days 12 and 14, CJ-1 had bleeding gums and balance problems and was 
euthanized on day 14 due to a body temperature below $35^{\circ} \mathrm{C}$ (Fig. $4 \mathrm{C}$ and $\mathrm{D}$, upper panels, pink lines). CJ-2 (Fig. 4C, upper panel, dark blue line) was euthanized on day 12 after losing consciousness and convulsing. CJ-3 experienced epistaxis and shivering starting from day 11 and was euthanized on day 14 (Fig. 4C, upper panel, light blue line). All VJ-P and VJ-PB monkeys survived the infection with clinical scores below 4 (Fig. 4C, lower panels). Most monkeys in these two groups only showed a transient increase in body temperature between days 6 and 12, which was less prolonged for VJ-P1 and VJ-PB1 (Fig. 4D, lower panels). VJ-PB2 did not show any increase in body temperature. Thus, MeV-NP vaccination induced long-term protection against the homologous LASV strain and a prime-boost immunization regimen had only a limited effect on the efficacy of protection relative to prime-only immunization.

The increase in plasma concentrations of alanine aminotransferase (ALT) and aspartate aminotransferase (AST), a hallmark of Lassa fever, was elevated in monkeys of the CB and CJ groups between day 9 and the day of euthanasia, but remained remarkably low in the CN monkeys (Fig. 4E, upper and middle panels). These differences in ALT and AST concentrations were particularly marked at day 12 between $C N$ and $C B$ monkeys $(P=0.0075$ for ALT; $P=0.0371$ for AST; Fig. 4F). This observation, combined with milder disease in CN monkeys, suggests that the lineage II strain used in this study is less pathogenic in monkeys than the strains from lineage IV and lineage VII. Similarly, the higher ALT and AST concentrations observed in the CB monkeys suggest that the lineage VII strain may cause more severe disease than the two other strains. ALT and AST concentrations remained low in all MeV-NP immunized monkeys (VB, VN, VJ-P and VJ-PB). The concentration of C-reactive protein (CRP) in the blood peaked at the time of death in all controls, except for $\mathrm{CN}-2$, whose CRP concentration peaked at day 15 , remained high at day 22 , and then fell to normal values by the end of the experiment (Fig. 4E, lower panels). The CRP concentration peaked at day 9 for all MeV-NP vaccinated monkeys and then decreased by day 15, suggesting that they had cleared LASV infection. Only VB-2 showed a transient rebound in CRP concentration at day 22 (Fig. 4E, lower left panel). The other biological parameters did not differ between the control and MeV-NP vaccinated monkeys, except for an increase in the urea concentration for the control monkeys shortly before death (fig. S1A to C). The CJ monkeys also showed higher concentrations of lactate dehydrogenase $(\mathrm{LDH})$ in the blood than the VJ-P and VJ-PB monkeys $(P$ 
$<0.0001$ at day 12) and low albumin (ALB) concentrations at the time of death (fig. S1D). Thus, $\mathrm{MeV}-\mathrm{NP}$ vaccination prevented the appearance of biological dysfunction associated with Lassa fever in monkeys.

\section{Control of LASV replication in immunized monkeys}

We measured the number of infectious particles (Fig. 5A and B) and copies of viral RNA (Fig. $5 C$ and $D$ ) in the plasma and swabs of all monkeys. Viremia increased substantially until the time of death from day 3 for the $\mathrm{CB}$ controls or day 6 for the $\mathrm{CN}$ and $\mathrm{CJ}$ controls for all controls that were euthanized before day 15 , reaching infectious titers between $10^{5}$ and $10^{6} \mathrm{FFU} / \mathrm{mL}$ of plasma (Fig. 5A and B, upper panels; fig. S2A and B, upper panels), with corresponding amounts of viral RNA between $10^{8}$ and $10^{9}$ copies/mL (Fig. $5 C$ and D, upper panels; fig. S2C and D, upper panels). $\mathrm{CN}-3$ showed lower viremia, approximately $10^{5} \mathrm{FFU} / \mathrm{mL}$ of plasma, which did not increase by the time of death on day 20 (fig. S2B, upper right panel, blue line). CN-2 showed only transient viremia, peaking at $1.4 \times 10^{3} \mathrm{FFU} / \mathrm{mL}$ on day 12 but no more infectious virus was detected in plasma isolated from $\mathrm{CN}-2$ by day 15 (fig. S2B, upper right panel, red line). We detected only trace amounts of viral RNA in the plasma of this monkey between day 15 and the end of the experiment (fig. S2D, upper right panel, red line). Infectious titers and viral RNA were also detected between days 9 and 15 in the oral or nasal swabs of most controls, but at lower amounts than the concentrations found in plasma (Fig. $5 A$ to $D$, middle and lower panels). We only detected a small number of infectious particles ( $300 \mathrm{FFU} / \mathrm{mL}$ ) in the oral swab of CN-2 (fig. S2B, lower right panel, red line) and a low number of viral RNA copies in swabs between days 9 and 12 (fig. S2D, center and lower right panels, red line). $\mathrm{CN}-2$ had thus controlled and cleared the infection by day 15 .

We measured low transient viremia (below $10^{4} \mathrm{FFU} / \mathrm{mL}$ ) and low infectious titers in swabs (below $10^{3} \mathrm{FFU} / \mathrm{mL}$ ) of vaccinated $\mathrm{VB}$ monkeys between days 6 and 9 and viral RNA in low quantities between days 3 and 15 (Fig. 5A and C, upper left panels; fig. S2A and C). We also detected a low degree of viremia, peaking at $600 \mathrm{FFU} / \mathrm{mL}$, and a low copy number of viral RNA in the plasma and swabs of $\mathrm{VN}-1$ (fig. S2B, upper left panel, orange line). None of the other vaccinated VN monkeys had detectable infectious titers or viral RNA in their fluids at any time of the experiment (Fig. 5A and C, right panels; fig. S2B and D). No infectious titers were found in the fluids of the VJ-P or VJ-PB monkeys, except for a low number of infectious particles in the nasal 
secretions on day 6 for VJ-P1 (700 FFU/mL) and day 9 for VJ-PB3 (200 FFU/mL) (Fig. 5B, middle panel; fig. S3A). However, we could still detect low amounts of viral RNA in the fluids of all monkeys, except VJ-PB2, between days 3 and 15 (Fig. 5D, right panels; fig. S3B).

We also determined infectious titers and viral loads within several organs at the time of necropsy (fig. S4A and B). Infectious particles and viral RNA were detected in all organs of the control monkeys, except for CN-2 (fig. S4A and B, left panels). Viral RNA was detectable in all organs of the $\mathrm{VB}$ and $\mathrm{VN}$ monkeys (fig. S4A, center and right panels), but not for all those of the VJ-P and VJ-PB monkeys (fig. S4B, center and right panels). The presence of viral RNA was not associated with infectious titers, except for very low titers ( $<20 \mathrm{FFU} / \mathrm{mL}$ ) in the lymphoid organs and liver of one CB and two CN monkeys (fig. S4A, left panel).

As viral RNA was detected in the brain of most vaccinated monkeys at the time of necropsy, we evaluated them for neurologic sequelae through anatomopathological analyses. We performed immunohistochemistry to identify presence of viral antigens in the brains of autopsied monkeys (fig. S5). All controls except CN-2 (fig. S5A, upper right panel) had LASV-infected endothelial cells

in their brain. Brains isolated from vaccinated monkeys did not exhibit any viral antigen staining after a heterologous (fig. S5A) or a homologous challenge (fig. S5B) at the time of necropsy. Thus, a single shot of MeV-NP led to control of viral replication in monkeys infected with heterologous strains from lineage II and VII or in monkeys infected with a homologous strain more than a year after immunization, demonstrating the induction of a long-term immunity.

\section{Antibody responses induced after LASV challenge}

We next sought to gain further insight into the mechanism of protection. To do so, we determined the LASV-specific immunoglobulin titers in monkeys after infection. In VB monkeys, the LASV-specific IgG titers against the heterologous strain from lineage VII rapidly rose from day 3 to reach a maximum at day 9 post-challenge (Fig. 6A, upper panel, orange line). We observed a similar increase in the IgG titers against the lineage II strain for the VN monkeys (Fig. 6A, center panel, red line). The VB and VN monkeys also produced high titers of lineage IV-specific IgG at day 9 (Fig. 6A, lower panel, orange and red lines). LASV-specific IgG directed against whole antigens of the heterologous lineages II and VII or homologous lineage IV also appeared in the 
control monkeys at day 6 in CN monkeys (blue lines) and at day 9 in CB monkeys (grey lines) (Fig. $6 \mathrm{~A}$, lower panel). By the time of death, all CB and CN controls had IgG titers similar to those of the VB and VN monkeys. We also measured the titers of IgG directed specifically against LASV NP and GP antigens (Fig. 6B). Titers reached their maximum concentrations between day 9 and day 12 after challenge for both the VB and VN monkeys. In controls, anti-NP and anti-GP IgG reached similar titers by the time of death, but their appearance was delayed compared to vaccinated monkeys.

The homologous response against lineage IV reached a maximum on day 15 for the VJ-P and VJ-PB monkeys (Fig. 6C upper panel, red and blue lines) and LASV-specific IgG also crossreacted with lineage VII and lineage II antigens (Fig. 6C, center and lower panels, red and blue lines). A few monkeys in these two groups had titers of IgG cross-reacting with lineage II at the time of challenge. The concentrations of LASV-specific IgG for the CJ monkeys increased from day 6 to the time of death but their appearance was delayed compared to VJ-P and VJ-PB monkeys (Fig. 6C, grey lines). Plasma from all VJ-P and VJ-PB vaccinated monkeys contained LASV NP- and GP-specific IgG at the time of challenge (Fig. 6D). Antibody titers were significantly higher in VJ-P and VJ-PB monkeys compared to controls at day 9 for NP $(P=0.0167$, Fig. 6D) and 12 for GP $(P=$ 0.0173, Fig. 6D). In CJ controls, anti-NP and anti-GP IgG were detected at day 9 and day 12, respectively (Fig. 6D). Whereas anti-NP IgG reached similar titers in vaccinated and control monkeys by the time of death, anti-GP IgG remained significantly lower in controls $(P=0.0195$, Fig. 6D).

We assessed the neutralizing potential of the anti-LASV antibodies produced in these monkeys. VB and VN monkeys had no NAbs against heterologous or homologous lineages at the time of challenge (Fig. 6E), with the exception of $\mathrm{VN}-2$, which had a low NAb titer directed solely against the homologous lineage IV (Fig. 6E, right panel). However, NAbs specific for the homologous and heterologous lineages were detected for all VB and VN monkeys by day 15 and persisted for most monkeys until day 28 (Fig. 6E, orange and red circles). No CB monkeys developed NAbs against lineage VII (Fig. 6E, left panel, blue circles) or lineage IV (Fig. 6E, right panel, blue circles) before death. CN-1 did not develop NAbs against lineage II or lineage IV, but $\mathrm{CN}-2$ and $\mathrm{CN}-3$ produced NAbs against both lineages at the time of euthanasia (day 28 for $\mathrm{CN}-2$ 
and day 20 for $\mathrm{CN}-3$ ) (Fig. 6E, grey circles). CJ monkeys never developed NAbs, whereas all VJ-P and VJ-PB monkeys showed neutralizing titers against the homologous strain by day 15 (Fig. 6F), with VJ-P2 demonstrating the highest neutralizing titer at day 15. MeV-NP vaccination induced the rapid production of cross-reactive and neutralizing anti-LASV antibodies after challenge in monkeys.

To evaluate the non-neutralizing functions of anti-LASV antibodies during the course of infection, we performed an antibody-dependent cell cytotoxicity (ADCC) assay on plasma samples collected before challenge or at several time points post challenge (30). In monkeys challenged with heterologous strains (Fig. 6G), the proportion of CD107a-expressing NK cells increased between day 0 and day 15 when incubated with plasma of all monkeys except for VN monkeys, for which a significantly lower activity than for $\mathrm{CN}$ was measured at day $15(P=0.027$, Fig. $6 \mathrm{G})$. Significant differences were also observed at day 0 and 28 between immunized monkeys $(P=$ 0.034 at day $0, P=0.039$ at day 28 , Fig $6 \mathrm{G}$ ). With the plasma from monkeys challenged one year after vaccination, the proportion of CD107a-expressing NK cells also increased between day 0 and day 15 in VJ-PB and CJ monkeys, but not in VJ-P monkeys (Fig. 6H). After incubation with plasma from VJ-P monkeys, the proportion of CD107a-expressing NK cells was higher than in CJ at day 6 $(P=0.025)$ and decreased over time.

\section{T cell responses induced after challenge}

After the challenge with heterologous LASV strains, we detected T cells producing cytokines in response to Josiah GPC peptides beginning at 9 days post infection for immunized monkeys (Fig. 7A and B). In VB and VN monkeys, $C D 8^{+} \mathrm{T}$ cell responses induced by LASV Nigeria and LASV Benin GPC-derived peptides were delayed compared to LASV Josiah GPC peptides (Fig. 7C) whereas similar kinetics were observed for $\mathrm{CD}^{+} \mathrm{T}$ cell responses after stimulation with GPC peptides derived from the different LASV strains (Fig. 7D). We detected CD8 ${ }^{+} \mathrm{T}$ cells producing cytokines in response to Josiah NP peptides at 12 days post infection for all immunized monkeys, starting at day 9 post infection in VB monkeys (Fig. 7E). The $\mathrm{CD} 8^{+} \mathrm{T}$ cell responses induced by LASV Benin or LASV Nigeria NP-derived peptides were negligible (Fig. 7F). The T cell responses were negligible for control monkeys, except for the two CN monkeys who survived longer, for which some cytokine-producing $T$ cells were detected at the time of death, mainly $C D 8^{+} T$ cells 
responding to LASV GPC peptides (Fig. 7A and B). In contrast to the post immunization responses, most CD8 ${ }^{+}$T cells produced only IFN- $\gamma$ and some both TNF- $\alpha$ and IFN- $\gamma$ (Fig. 7A, C, E and F, pie charts). The same was true for $\mathrm{CD}^{+} \mathrm{T}$ cells, but a larger proportion of TNF- $\alpha^{+}$IFN- $\gamma^{+}$cells was induced (Fig. 7B and D, pie charts).

We also observed cytokine-producing $\mathrm{T}$ cells from 9 days post infection in monkeys challenged one year after immunization, with 0.4 to $0.7 \%$ responding $\mathrm{CD}^{+}$and $\mathrm{CD} 4^{+} \mathrm{T}$ cells after stimulation with GPC- and NP-derived peptides by day 12, when the peak of T cell responses was observed (Fig. 8). Thereafter, the T cell response decreased over time. A similar percentage of CD8 ${ }^{+}$ T cells produced cytokines in response to Josiah GPC peptides 12 days post infection was observed in both VJ-P and VJ-PB monkeys, but only VJ-P monkeys presented a significant increase in the percentage compared to $C J$ monkeys ( $P=0.041$, Fig. $8 \mathrm{~A}$ ). In response to Josiah NP peptides, the production of cytokines by $C D 8^{+} \mathrm{T}$ cells from VJ-P and VJ-PB was not significant and presented a large variability $(P>0.05$, Fig. $8 \mathrm{~B})$. Although the percentage of $C D 4^{+} \mathrm{T}$ cells producing cytokines in response to Josiah GPC peptides was similar between VJ-P and VJ-PB at day 12 post infection, responding cells appeared earlier in VJ-P compared to VJ-PB (Fig. 8C). In response to Josiah NP peptides, a significantly higher percentage of $\mathrm{CD}^{+} \mathrm{T}$ cells produced cytokines in VJ-PB monkeys compared to CJ monkeys ( $P=0.036$, Fig. 8D). In contrast, negligible T cell activation was observed for control monkeys during the whole course of LASV infection (Fig. 8A to D). Overall, the primeboost immunization regimen did not improve $T$ cell responses over those induced by prime-only vaccination. Again, the responses mainly consisted of TNF- $\alpha^{-}$IFN- $\gamma^{+}$CD8 $8^{+}$T cells and TNF- $\alpha^{-}$IFN$\gamma^{+}$and TNF- $\alpha^{+}$IFN $-\gamma^{+}$CD4 ${ }^{+}$T cells (Fig. 8, pie charts). Similar percentages of CD4 ${ }^{+}$T cells expressed CD154, a co-stimulation molecule expressed by antigen-specific CD4 ${ }^{+} \mathrm{T}$ cells (31), after stimulation with GPC- and NP-derived peptides for all immunized monkeys (Fig. 8E). The peak of expression of CD154 was observed 12 days after infection in response to Josiah GPC and NP peptides, and thereafter decrease over time, as observed with production of cytokines. Again, there was no difference in the intensity of the response between the prime-only and prime-boost regimens $(P$ $>0.05$, Fig. 8E). 


\section{DISCUSSION}

Here, we demonstrated the ability of the MeV-NP vaccine to protect against divergent LASV strains and confer long-term immunity after a single shot. The large and increasing genetic diversity of LASV strains is challenging, and a vaccine should confer full protection against existing and emerging LASV strains. Indeed, new viral lineages have recently emerged (7) and the circulation area of LASV is expanding $(32,33)$. We chose to use LASV strains belonging to lineages II and VII that were isolated in 2016 (7). Our rationale was that lineage II, along with the closely related lineage III, represents the strains circulating in Nigeria, the most highly endemic country for Lassa fever. Lineage VII is highly divergent from the Josiah strain used to generate our vaccine but is also interesting because of its recent emergence and high degree of lethality in humans, estimated to be between 30 and 50\% (7). Lineage $\mathrm{VI}$ viral strains have never been associated with human cases and lineage $V$ strains are close to those of lineage IV and present lower pathogenicity in monkeys $(34,35)$. Therefore, the protection achieved against lineage II and VII LASV strains suggests that the MeV-NP vaccine would be efficient against all circulating strains of LASV capable of infecting humans. Previous studies used lineage I, lineage II, homologous lineage IV, or closelyrelated lineage $V$ strains $(17,19,36,37)$. We show, for the first time, that the lineage VII LASV strain is highly pathogenic in monkeys, with a uniformly lethal Lassa fever at least as severe as that caused by the Josiah strain. In contrast, the lineage II strain used in this study, LASV Nigeria, appears to be less severe in non-human primates, with one control monkey surviving acute Lassa fever and the death of another delayed relative to that caused by the other strains.

We used two different routes of vaccine inoculation during these experiments. The monkeys challenged with heterologous strains were immunized using the same subcutaneous (SC) route and dose as that used for the first pre-clinical evaluation (10) and, as previously reported,

neither adverse effects nor vaccine shedding or viremia were observed. Lower doses of vaccine and the intramuscular (IM) route are used for clinical trials in humans. Thus, monkeys challenged one year after immunization received either $10^{5}$ (prime-boost) or $10^{6}$ (prime only) $\mathrm{TCID}_{50}$ by the IM route, $10^{5}$ corresponding to the highest dose used in the phase 1 study in humans. Neither 
shedding nor adverse effects were observed. Overall, these data confirm the safety of the MeV$\mathrm{NP}$ vaccine in monkeys.

As previously reported (10), inconsistent LASV IgM responses were induced after immunization with MeV-NP and no NAbs were detected. IgG specific for LASV-derived antigens appeared at low titers after vaccination in the prime-only regimen, but with different kinetics depending on the route of immunization. Although LASV IgG were detected two to three weeks after immunization by the SC route, they appeared later when the IM route was used. The reason for this discrepancy is unclear, as $\lg G$ directed against heterologous antigens were detected from two weeks after immunization in other studies using the same Schwartz vaccine vector and IM route (38-40). IgG directed against both GPC and NP expressed by the vaccine were induced at similar concentrations and were detected at earlier timepoints than previously observed (10), probably due to the higher sensitivity of the recombinant protein-based enzyme-linked immunosorbent assay (ELISA) than the native antigen-based assay.

Although 10-fold less MeV-NP particles were injected during the prime-boost regimen relative to the prime-only regimen for the long-term immunization experiment, the two-dose regimen clearly improved the humoral response. IgG induced by Josiah-derived antigens recognized lineage VII antigens, whereas the lack of lineage II antigen recognition was probably due to the lower sensitivity of the assay or the low titers of IgG induced after the single immunization. The induced humoral responses persisted for at least one year after the primeboost immunization, whereas LASV IgG were detected in only half of the monkeys at day 317 after a single vaccination and in none at $383 \mathrm{DPI}$. As previously observed (10), a moderate but notable percentage of $\mathrm{CD}^{+}$and $\mathrm{CD}^{+}{ }^{+}$T cells producing mainly TNF- $\alpha$ and not IFN- $\gamma$ in response to GPCand NP-derived peptides circulated after immunization. The intensity of the $T$ cell responses induced by our vaccine was similar to that observed with other candidates in monkeys $(18,41)$. T cells induced by LASV Josiah-derived antigens were able to recognize LASV Benin- and LASV Nigeria-derived antigens, confirming that the MeV-NP vaccine is able to induce T cells with broad specificity against LASV diversity and demonstrating the ability of vaccine-induced T cells to cross react with heterologous LASV strains. Such cross-reactivity was expected, as common immunodominant peptides have been described for T cell responses induced in survivors infected 
with different LASV lineages $(42,43)$. A lower percentage of specific T cells was observed with heterologous strains compared to Josiah LASV in response to NP, but not to GPC. This may be due to the lower amino acid homology between strains observed for NP than for GPC. Nevertheless, this lower recognition of heterologous LASV NP is still compatible with the improved efficacy of a vaccine expressing both GPC and NP. Indeed, several reports suggest that GPC is required for a LASV vaccine and that the presence of NP improves efficacy $(36,44)$, particularly if the immunosuppressive exonuclease domain of LASV NP is abrogated (10). Having the NP in addition to GPC could help to protect against heterologous strains and may induce a more durable immunity, as suggested by the efficacy of the ML29 candidate, also based on the expression of Josiah LASV GPC and NP, against lineage II LASV (36).

As for the humoral responses, the kinetics of the T cell responses differed according to the immunization routes, with the peak of responding T cells observed later following immunization by the IM route. Once again, we have no explanation for such a difference. In contrast to the results obtained for LASV IgG, boosting monkeys did not improve T cell responses. The maximum percentage of LASV-specific T cells was even measured one week later than in monkeys that received a single IM shot. This delayed response probably resulted from the lower dose of vaccine used for the prime-boost regimen. The lack of a boost effect may be due to the difference in dose, but similar observations were described for other MeV-based vaccine candidates independently of dose differences $(38,39)$, suggesting that T cells might not benefit from a prime-boost strategy. The production of cytokine by T cells in response to LASV-derived peptides was only detected a few weeks after immunization, probably reflecting the effector phase of the response. In vitro stimulation of PBMCs with LASV peptides followed by a short-term culture demonstrated that memory $\mathrm{T}$ cells with cytotoxic potential were still present in the circulation one year after immunization. Therefore, MeV-NP induced humoral and cellular responses that persist at least one year, even after a single shot.

All immunized monkeys were protected after the challenge, regardless of the LASV strain used, even one year after immunization for the homologous Josiah strain. The efficacy of a single dose of MeV-NP after one year is similar to the protection observed when monkeys were challenged one month after immunization (10), with no clinical signs, no alteration of biological 
parameters, and only a transient increase in body temperature. Moreover, infectious LASV was not detected in plasma nor in most of the swabs, although we detected elevated transient viral RNA load in plasma and swabs, as well as residual viral loads in organs as compared to previous studies evaluating monkeys challenged one month after vaccination. Overall, the protection sustained after one year was similar for the prime-boost regimen, aside from one monkey in the prime-boost group that exhibited sterilizing immunity, suggesting that one high-dose shot provides comparable long-term immunity as a two low-dose regimen. This is an important finding, as a one-dose vaccine would provide a valuable advantage in endemic countries to perform mass vaccination or a ring vaccination strategy during an outbreak. A vaccine also has to confer longterm immunity, as regular boosts would be difficult to perform in endemic countries. Our results suggest that the MeV-NP vaccine generates robust long-term immunity. In contrast, a VSV-based vaccine expressing LASV GPC protected only $71 \%$ of guinea pigs one year after immunization (37).

A single shot of MeV-NP confers efficient protection against a lineage II LASV strain. No clinical signs were observed after challenge, and biological parameters were not altered. Viral replication was efficiently controlled in these immunized monkeys, as only very low and transient viremia was detected in the plasma but not in swabs, and only one monkey showed traces of infectious LASV in the spleen and liver. A low concentration of residual viral RNA was present in the organs at the necropsy, confirming that the monkeys were fully protected against the disease, but that the immunity was not sterilizing. These results are consistent with those obtained in monkeys immunized with the VSV-based vaccine and challenged with a lineage II LASV strain, with measurable viral replication (17). MeV-NP-immunized monkeys were also protected against lineage VII LASV, with no alteration of biological parameters, but some mild signs were transiently observed, together with a transient increase of body temperature. A low degree of viral replication occurred in these monkeys, with a transient infection and viral RNA load in the plasma and swabs. The residual viral load in the organs was similar to that observed in lineage II-challenged immunized monkeys. Low concentrations of LASV RNA were found in the brains of immunized monkeys, but no viral antigen was detected in brain sections. Moreover, no neurological signs were observed in immunized monkeys, confirming that no neurological lesion was induced. This difference in protection relative to that against lineage II LASV is probably due to the high 
pathogenicity of Benin LASV in monkeys and the large genetic diversity between lineage IV and VII. As lineage VII LASV has never been evaluated before, the ability of other vaccines to protect against this strain is unclear. Given its high pathogenicity and genetic distance from the Josiah strain, lineage VII is likely a pertinent strain that should be used for future vaccine challenge studies. Cross-protection against less divergent strains, such as non-Josiah lineage IV strains or lineage $V$ strains, which also show lower pathogenicity, is relatively easy to achieve (19). Given the large and increasing genetic diversity of circulating LASV strains $(2,7,8,45,46)$, it is crucial to validate vaccines against those that are the most challenging.

As previously reported (10), both humoral and cellular responses were markedly boosted after challenge. High titers of LASV-specific IgG were induced in the first week after infection, regardless of the LASV strain used. Antibodies recognized lineage II and VII antigens with the same efficiency as for homologous Josiah LASV antigens, confirming the potential cross-reactivity against the entire diversity of LASV. High concentrations of LASV IgG were also induced in control monkeys, but later during the course of Lassa fever. NAbs were induced at moderate titers in all immunized monkeys two weeks after infection, as well as in the surviving lineage Il-infected control monkey. The NAbs were equally potent against both homologous and heterologous LASV strains, confirming once again their cross-reactivity. Interestingly, higher titers of NAbs were induced when the monkeys were challenged one year after immunization. This discrepancy could be due either to the longer period before the challenge or the infection with homologous LASV. Moreover, maturation of antibody response through somatic hypermutation could also explain this observation. There was no notable difference between the prime-only and prime-boost regimens in terms of the humoral response when the monkeys were challenged one year after immunization. T cell responses were also boosted after challenge with the Josiah strain. Again, there were no observable differences between the prime-only and prime-boost monkeys. The GPC- and NPspecific $\mathrm{CD}^{+}$and $\mathrm{CD}^{+} \mathrm{T}$ cell responses were of similar intensity as those observed when the monkeys were challenged one month after a single shot of MeV-NP (10), suggesting that the T cell immunity induced by MeV-NP vaccination is long-lasting. In addition, the diversity of T cell phenotypes was similar to that observed with a one-month post-immunization challenge (10). $\mathrm{CD}^{+} \mathrm{T}$ cells also expressed CD154 in response to peptide stimulation, confirming their activation 
and specificity to LASV $(31,47)$. These results are highly encouraging, as T cells are required for the control of LASV infection $(10,16,18,44,48)$. The intensity of the $T$ cell responses induced after the challenge with heterologous strains were lower than those against Josiah LASV (10), probably because only epitopes conserved between the different LASV lineages were able to reactivate the Josiah-specific memory T cells. Consistently, major histocompatibility complex I- and II-specific epitopes conserved between LASV lineages and other arenaviruses have been described (16, 43, 49, 50), suggesting that Josiah LASV-specific T cells may protect against divergent LASV strains. We did not detect T cells producing cytokines in non-immunized monkeys challenged with lineage II or VII LASV, except for some $\mathrm{CD}^{+} \mathrm{T}$ cells detected 20 days post infection in one lineage IIinfected control monkey. Only a low percentage of responding T cells was measured 28 days post challenge in the surviving control monkey. The lower intensity of $\mathrm{T}$ cell responses induced by heterologous LASV relative to a homologous challenge may have been involved in the difference in the efficacy of the control of viral replication observed in the MeV-NP-immunized monkeys.

Our study has several limitations. Our results did not allow to clearly identify the mechanisms involved in the control of LASV after immunization. Both humoral and cellular immune responses are induced by the vaccine and are strongly boosted after the challenge coincidently with the control of viral replication. In addition, NAbs appeared in all immunized monkeys during the course of LASV infection. However, their absence at the time of challenge and until one to two weeks later suggests that even if they participate in protection, Nabs are poor predictors of vaccine effectiveness, consistent with our previous observations (10). Passive transfer of neutralizing human monoclonal antibodies can control Lassa fever in non-human primates and may also act in humans. However, as we failed to detect NAb in the plasma of immunized nonhuman primates before the challenge and because only moderate concentrations of nonneutralizing LASV IgG were present, it is unlikely that passive transfer of this material could be efficient against a challenge and that the control of LASV in MeV-NP-immunized monkeys relies on direct neutralization of viral inoculum. Non-neutralizing IgG and, particularly, $C D 8^{+}$and $C D 4^{+}$ T cells are probably crucial for controlling LASV after MeV-NP immunization, as also suggested by previous studies $(10,44)$. The protection induced by a Lassa-Rabies vaccine was shown to be mediated by non-neutralizing LASV-specific IgG through ADCC and phagocytosis (ADCP) (51). In 
our study, ADCC was not correlated with protection as both control and immunized monkeys developed antibodies able to trigger ADCC. For cross-protection experiments, ADCC-inducing ability of the plasma was equivalent between control and immunized monkeys over the disease course, arguing against a primary role of this mechanisms in the protection. In contrast, plasma of immunized monkeys induced ADCC in the first days after challenge in the long-term experiment. It is therefore difficult to make conclusions on the role of $A D C C$ in the protection induced by MeVNP. A limitation of our study is the lack of identification of the immune correlates of protection. Although our data point towards a preponderant role of T cell responses, the depletion of $\mathrm{CD} 4^{+}$ and $\mathrm{CD}^{+} \mathrm{T}$ cell before the challenge would confirm the role of cellular immunity after MeV-NP vaccination and represents a future direction for the field. The number of monkeys used in the experiments is another limitation of our study. Our BSL-4 animal facilities can only accommodate 12 monkeys, in agreement with animal welfare and the need to reduce animal use.

Lassa fever is an increasing threat to public health in West Africa because of the wide distribution of natural reservoirs of LASV and the frequent introduction of LASV into the human population (2). In total, 180 million people are considered to be at risk for Lassa fever (4) and they often live in remote areas with limited diagnosis and poor healthcare structures. In addition, there is no effective treatment available aside from the reference treatment, ribavirin, for which the true effectiveness is debatable (52). Thus, the most efficient way to combat Lassa fever is to perform mass vaccination in endemic areas using an efficient vaccine that is able to confer long-term immunity against the entire diversity of LASV with a minimum number of doses. The results provided here suggest that MeV-NP could be one such candidate, as it induces long-term protective immunity after a single dose and protects against highly pathogenic LASV strains that are highly divergent from the Josiah strain. Moreover, the $\mathrm{MeV}$ vaccine is known to be safe and clinical trials of other MeV-based vaccines have confirmed that adding heterologous antigens to the MeV backbone does not modify the safety profile of the vaccine $(23,24,53)$. The MeV-NP candidate is currently being evaluated in humans in a phase 1 trial (NCT04055454) and a phase 2 trial is in preparation. 


\section{MATERIALS AND METHODS}

\section{Study design}

Our objectives were to evaluate the efficacy of MeV-NP, a recombinant measles Schwarz vaccine expressing LASV GPC and NP, against heterologous LASV strains from lineages II and VII (crossprotection study) and its ability to confer long-term protection against the homologous strain from lineage IV (long-term protection study). Both studies were carried out on female monkeys (Macaca fascicularis, 17-27 months old, 2 to $3 \mathrm{~kg}$ ). In the cross-protection study, groups of three monkeys were immunized in A2 facilities (SILABE) by subcutaneous (SC) injection of $2 \times 10^{6} \mathrm{TCID}_{50}$ of MeV-NP (two vaccinated groups) or MeV vaccine strain Schwarz (two control groups). Blood draws, oral and nasal swabs, and urine sampling were performed every two to three days during the first two weeks and then once a week up to day 37 . After 25 days, the monkeys were transported to biosafety level (BSL)-4 facilities (Laboratoire P4 INSERM-Jean Mérieux). At day 37, one MeV-NP vaccinated group and one control group were subcutaneously challenged with 3,000 focus-forming units (FFU) of LASV Nigeria (Lineage II strain BEN-16081) (7), the two other groups were challenged with 3,000 FFU of LASV Benin (lineage VII, strain BEN-16131) (7). In the long-term protection study, one group of four monkeys was immunized by a single intramuscular (IM) injection of $2 \times 10^{6} \mathrm{TCID}_{50}$ of MeV-NP and another group of four monkeys received two injections of $2 \times 10^{5} \mathrm{TCID}_{50}$ of MeV-NP 35 days apart. Another control group of three monkeys received two IM injections of $2 \times 10^{5} \mathrm{TCID}_{50}$ of MeV 35 days interval. After the first and second immunizations, blood draws, oral and nasal swabs, and urine sampling were performed every two to three days during the first two weeks and then once a week. Similar sampling was then performed every month for more than a year. Monkeys were transported to the BSL-4 facility 10 days before being challenge by a SC injection of 1,500 FFU of LASV Josiah (lineage IV strain). Monkeys from a single group were placed together in a chamber under negative pressure to avoid mixing with monkeys from other groups. Clinical follow-up was performed group by group to avoid mixing and therefore was not blinded.

After challenge, monkeys were followed for clinical signs and euthanized according to scoring based on body temperature, body weight, feeding, dehydration, behavior, and clinical signs (table 
S4). Blood draws, oral and nasal swabs, and urine sampling were performed every two to three days during the first two weeks and then once a week up to day 28. All monkeys reaching a clinical score of 15 were euthanized before the end of the experimentation (28 to 30 days after challenge) to limit their suffering. All procedures were approved by the Comité Régional d'Ethique en Matière d'Expérimentation Animale de Strasbourg (2018100414445313) and the Comite Régional d'Ethique pour l'Expérimentation Animale Rhône Alpes (2018101211262022 and 2019100810333758).

\section{Cell cultures, virus, and infections}

Vero NK and Vero E6 cells were grown in Glutamax Dulbecco Modified Eagle's Medium (DMEM, Life Technologies) supplemented with $5 \%$ fetal bovine serum (FBS) and $0.5 \%$ PenicillinStreptomycin. For the preparation of MeV-NP and MeV stocks, Vero NK cells were infected at a multiplicity of infection of 0.01 and then incubated at $37^{\circ} \mathrm{C}$ for two to three days. To harvest the virus, cells were scraped into Opti-Minimum Essential Medium (MEM) I reduced-serum medium and freeze-thawed twice. Titers were determined by $T C I D_{50}$ titration on Vero NK cells. Vaccine stocks for monkey immunization were prepared in 1\% DMEM. Stocks of LASV Josiah (kindly provided by S. Becker, Philipps-Universtität), LASV BEN-16081 Lineage II (LASV Nigeria), and LASV BEN-16131 Lineage VII (LASV Benin) were produced and titrated on Vero E6 cells. Inoculums were prepared in phosphate buffered saline (PBS). Monkeys received 1,500 FFU by the SC route for infection with the Josiah strain and 3,000 FFU by the same route for BEN-16081 and BEN-16131. Viral titers in plasma and organs were determined by titration on Vero E6 cells. For plaque reduction neutralization assays, plasma samples were diluted and mixed with $150 \mathrm{FFU}$ of LASV. After 1 hour, the mixtures were added to Vero E6 cells and incubated for 1 hour before addition of carboxymethylcellulose diluted in DMEM. After seven days, the number of foci was calculated by focus-forming immunodetection using anti-LASV antibodies, as described in (54).

\section{Quantitative RNA analysis}

Quantitative RT-PCR for viral RNA was performed with the SensiFAST Probe No-ROX One-Step kit (Bioline) using NP-specific primers and probes for the Josiah (Forward (For): 5'CTTTCACCAGGGGTGTCT-3'; Reverse (Rev): 5'-GTCACCTCAGACAATGGATGG-3'; Probe (Pb): 5'TGAACATTCCAAGAGCC-3' , Nigeria (For: 5'-AGTATGTTCTCGTAAGGGTTC-3', Rev: 5'- 
ACTTCAGTTTAGGAGCTGC-3', Pb: 5'-TACACCTCAGACAATGGATGG-3'), and Benin (For: 5'-TAA GGATTCCTTTCTCCAG-3'; Rev: 5'-ACTCCCCAAACCATGGATG-3', Pb: 5'-TCCCAAGACTCCTCTTC-3') strains and quantified using corresponding NP-specific synthetic RNA standards developed in house (55). Reverse transcription was performed at $45^{\circ} \mathrm{C}$ for $10 \mathrm{~min}$. After an activation step at $95^{\circ} \mathrm{C}$ for $2 \mathrm{~min}$, amplification $\left(95^{\circ} \mathrm{C} 1 \mathrm{~min}, 52^{\circ} \mathrm{C} 30 \mathrm{sec}\right.$ ) was repeated for 45 cycles, then reaction was cooled down to $37^{\circ} \mathrm{C}$. Limits of detection were 4284 RNA copies per $\mathrm{mL}$ for LASV Josiah and Benin, 42840 copies per $\mathrm{mL}$ for LASV Nigeria.

\section{Immunohistochemistry}

At death, tissues were collected and fixated for a minimum of 14 days in $10 \%$ formalin. The samples were then dehydrated using a STP120 (Microm Microtech) and paraffin-embedded with a TES99 device (Tech-Inter). Three micrometers tissue sections were prepared using a Leica LM2125 RTS microtome and unmasking was performed in a citrate buffer using a Retriever 2100 (Prestige Medical). Brain tissue sections were blocked for 30 min in PBS BSA 3\% and LASV immunostaining was performed using an anti-GP2c mouse monoclonal antibody (L52-272-7, kindly provided by P. Jahrling, United States Army Medical Research Institute of Infectious Diseases, USAMRIID) at a 1:50 dilution overnight, detected with an anti-mouse secondary antibody coupled with a peroxidase (N-Histofine, Microm Microtech). 3-Amino-9-ethylcarbazole (Sigma-Aldrich) was used to stain the tissue sections, and they were counterstained with hematoxylin (Leica) before observation with a Dmi8 Leica microscope. Images were taken with the LASX software (Leica).

\section{T cell activation assay}

LASV-specific T cells were analyzed from $200 \mu$ fresh whole blood. Cells were incubated with overlapping GPC or NP peptides and anti-human CD28 and anti-human CD49d antibodies (2 $\mu \mathrm{g} / \mathrm{ml}, \mathrm{BD}$ Biosciences) and Brefeldin A (10 $\mu \mathrm{g} / \mathrm{ml}$, Sigma-Aldrich) for 6 hours at $37^{\circ} \mathrm{C}$. Staphylococcus enterotoxin A (SEA) $(1 \mu \mathrm{g} / \mathrm{ml}$, Sigma-Aldrich) and PBS were used as positive and negative activation controls, respectively. The peptides ( $1 \mu \mathrm{g} / \mathrm{ml}$ each) were 15 amino acids long with an overlap of 11 residues and spanned the complete LASV GPC or NP (Josiah, Nigeria, or Benin strains). PBS-ethylene diamine triacetic acid (EDTA) (2 mM final concentration) was added to the samples before staining for CD3 (clone SP34-2, APC, $14 \mu \mathrm{L}$ per sample), CD4 (clone L200, Alexa Fluor 700, $5 \mu \mathrm{L}$ per sample), and CD8 (clone SK1, APC-H7, $5 \mu \mathrm{L}$ per sample) (BD Biosciences) 
in presence of Live-Dead stain (Thermo Fisher Scientific) for 30 min at $4^{\circ} \mathrm{C}$ in the dark. Red blood cells were then lysed using PharmLyse (BD Biosciences). Cells were fixed and permeabilized using the FoxP3 staining buffer set (Miltenyi Biotec) following manufacturer's instructions before intracellular staining with antibodies against IFN- $\gamma$ (clone B27, PE, $20 \mu \mathrm{L}$ per sample), and TNF- $\alpha$ (clone Mab11, Pe-Cy7, $5 \mu \mathrm{L}$ per sample) (BD Biosciences) and, in some experiments, to CD154 (clone 5C8, VioBlue, $2 \mu \mathrm{L}$ per sample) (Miltenyi Biotec) for $30 \mathrm{~min}$ at $4^{\circ} \mathrm{C}$ in the dark. Cells were analyzed by flow cytometry using an LSR Fortessa cytometer (BD Biosciences) or a 10-color Gallios cytometer (Beckman Coulter). Data were analyzed using Kaluza 2.0 software (Beckman Coulter).

\section{T cell reactivation assays}

Thawed PBMCs were plated in 96-well plates at 250,000 cells per well in RPMI-1640 with Glutamax (Life Technologies) supplemented with $10 \%$ heat inactivated cynomolgus monkey plasma, $0.5 \%$ Penicillin-Streptomycin, $1 \%$ non-essential amino acids, $25 \mathrm{mM}$ Hepes and $1 \mathrm{mM}$ sodium pyruvate and incubated overnight at $37^{\circ} \mathrm{C}$ and $5 \% \mathrm{CO}_{2}$. PBMCs were then mock-stimulated or stimulated with overlapping GPC or NP peptides and anti-human CD28 and anti-human CD49d antibodies (2 $\mu \mathrm{g} / \mathrm{ml}, \mathrm{BD}$ Biosciences). One and two days later, interleukin (IL)-2 and IL-7 (Miltenyi Biotec) were added at $10 \mathrm{U} / \mathrm{mL}$. Five days post peptide stimulation, cells were stained with CD3 (clone SP34-2, V450, $1.25 \mu \mathrm{L}$ per sample), CD4 (clone L200, APC at $5 \mu \mathrm{L}$ per sample or Alexa Fluor 700 at $1.25 \mu \mathrm{L}$ per sample), CD8 (clone SK1, APC-H7, $1.25 \mu \mathrm{L}$ per sample), CD134 (clone L106, PE, $5 \mu \mathrm{L}$ per sample), CD69 (clone FN50, PerCP-Cy5.5, $1.25 \mu \mathrm{L}$ per sample), CD27 (clone M-T271, PE, $5 \mu \mathrm{L}$ per sample), CD28 (clone CD28.2, PE-CF594, $1.25 \mu \mathrm{L}$ per sample), CD45RA (clone 5H9, PE-Cy7, $1.25 \mu \mathrm{L}$ per sample), CD95 (clone DX2, APC, $2.5 \mu \mathrm{L}$ per sample) (BD Biosciences), HLA-DR (clone AC122, FITC, $0.5 \mu \mathrm{L}$ per sample) CCR7 (clone REA546, PerCP-Vio700, $0.5 \mu \mathrm{L}$ per sample) (Miltenyi Biotec), CD137 (clone 4B4-1, PE-Cy7, $2.5 \mu \mathrm{L}$ per sample), CD279 (clone EH12.2H7, PE/Dazzle 594, $2.5 \mu \mathrm{L}$ per sample), (BioLegend) and CD38 (clone AT-1, FITC, $5 \mu \mathrm{L}$ per sample) (STEMCELL) antibodies for 30 min at $4^{\circ} \mathrm{C}$ in the dark in presence of Live-Dead stain (Thermo Fisher Scientific). Cells were permeabilized using the FoxP3 staining buffer set (Miltenyi Biotec) per manufacturer's instructions and stained with Ki67 (clone B56, PE-Cy7, $1.25 \mu \mathrm{L}$ per sample), GrzB (clone GB11, PE, $1.25 \mu \mathrm{L}$ per sample) (BD Biosciences) and perforin (clone Pf-344, FITC, $1.25 \mu \mathrm{L}$ per sample) (Mabtech) 
antibodies. Cells were analyzed by flow cytometry using an LSR Fortessa cytometer (BD Biosciences). Data were analyzed using Kaluza 2.0 software (Beckman Coulter).

\section{Hematology and biochemistry}

The number of circulating CD4 and CD8 T cells, B cells, NK cells, monocytes, and neutrophils was determined by flow cytometry using cell specific panels. Plasma concentrations of ALT and AST, $\mathrm{LDH}$, creatine kinase, amylase, total bilirubin, direct bilirubin, creatinine, urea, iron, UA, total proteins, ALB, and CRP were measured using a Pentra C200 analyzer (Horiba Medicals).

\section{Enzyme-linked immunosorbent assays}

For the determination of LASV-specific IgM antibody titers, Maxisorp plates (Nunc) were coated overnight at $4^{\circ} \mathrm{C}$ with antibodies directed against non-human primate IgM $\mu$-chain (SigmaAldrich). Coated plates were then blocked in PBS $/ 2.5 \%$ BSA for 2 hours at $37^{\circ} \mathrm{C}$ before incubation with diluted plasma $(1: 100,1: 400,1: 1,600)$ or positive and negative control sera for 1 hour at $37^{\circ} \mathrm{C}$. Lysates of LASV-infected (Josiah, Nigeria, or Benin) or mock-infected Vero E6 cells (lysed by freeze/thaw cycles for $\lg M$ antigens and in borate triton 1\% for $\lg G$ antigens), as positive and negative antigens, were then added to the plates for 2.5 hours at $37^{\circ} \mathrm{C}$ before incubating them in a cocktail of anti-LASV monoclonal antibodies (generously provided by P. Jahrling, USAMRIID) for 1 hour at $37^{\circ} \mathrm{C}$. Plates were further incubated with polyclonal peroxidase-conjugated antibodies (Sigma-Aldrich) directed against mouse $\lg \mathrm{Y} \gamma$-chain for 1 hour at $37^{\circ} \mathrm{C}$. For the determination of LASV-specific IgG antibody titers, Polysorp plates (Nunc) were coated overnight with a lysate of LASV-infected (Josiah, Nigeria, or Benin) or mock-infected Vero E6 cells, as positive and negative antigens, respectively. For the determination of Josiah NP and GP-specific IgG antibody titers, Maxisorp plates (Nunc) were coated overnight at $4^{\circ} \mathrm{C}$ with LASV Josiah recombinant NP C-ter and $\mathrm{N}$-ter $(2.5 \mu \mathrm{g} / \mathrm{mL}$ each) or prefusion GP (5 $\mathrm{g} / \mathrm{mL}$ ) (Zalgen). After blocking with PBS/2.5\% bovine serum albumin) for 1 hour, plasma samples were incubated for 1 hour on coated plates at dilutions of $1: 250,1: 1,000,1: 4,000$, and 1:16,000. Plates were further incubated with polyclonal peroxidaseconjugated antibodies directed against non-human primate IgG $\gamma$-chain (Sigma-Aldrich). Tetramethylbenzidine (TMB) (Eurobio) was used for detection for both IgM and IgG titer determination. The titer of positivity represented the highest dilution which gave a positive signal. The threshold of positivity was calculated as $2 \times$ mean of three negative plasma samples +1 
standard deviation of the mean. All samples were analyzed in duplicate and the results are presented as the means of duplicates.

\section{Antibody-dependent cell cytotoxicity assay.}

Maxisorp plates (Nunc) were coated overnight with recombinant LASV GP (Zalgen) or recombinant EBOV GP (R\&D systems) at a concentration of $5 \mu \mathrm{g} / \mathrm{mL}$ in sterile PBS. Plates were then washed in sterile PBS and incubated with heat-inactivated EDTA-anticoagulated plasma for 4 hours at $37^{\circ} \mathrm{C}$. Freshly isolated PBMCs from healthy naïve cynomolgus monkeys were then added to each well at 500,000 cells per well in the presence of anti-CD107a (clone H4A3, FITC, $10 \mu \mathrm{L}$ per sample), BD Biosciences) and brefeldin ( $10 \mu \mathrm{g} / \mathrm{ml}$, Sigma-Aldrich) and plates were incubated overnight at $37^{\circ} \mathrm{C}$. Cells were then stained with anti-CD20 (clone 2H7, BV421, $2.5 \mu \mathrm{L}$ per sample), anti-CD14 (clone TÜK4, APC, $1 \mu \mathrm{L}$ per sample), anti-CD3 (clone SP34-2, Alexa Fluor 700, $5 \mu \mathrm{L}$ per sample) and antiCD8 antibodies (clone SK1, APC-H7, $2.5 \mu \mathrm{L}$ per sample) (BD Biosciences) in presence of Live-Dead stain (Thermo Fisher Scientific), permeabilized using the FoxP3 staining buffer set (Miltenyi Biotec) per manufacturer's instructions, and stained with anti-IFN- $\gamma$ (clone B27, PE, $10 \mu \mathrm{L}$ per sample) and anti-Ki67 antibodies (clone B56, PE-Cy7, $2.5 \mu \mathrm{L}$ per sample) (BD Biosciences). Cells were analyzed by flow cytometry using a 10-color Gallios cytometer (Beckman Coulter). Data were analyzed using Kaluza 2.0 software (Beckman Coulter).

\section{Statistical analysis}

Statistical analyses of the flow cytometry data were performed using Sigma Plot 14 (Systat Software Inc.) Data were analyzed using a one-way or two-way analysis of variance (ANOVA) if the data set passed a normality test (Shapiro Wilk) and the equal variance test (Brown-Forsythe). If not, a Kruskal Wallis one-way ANOVA on ranks was used. All other statistical analyses were performed using GraphPad Prism 8. Data for continuous variables are expressed as individual points or as the mean \pm standard error of the mean (SEM). A Student's t-test or one-way ANOVA with multiple comparisons was used to compare the means between groups of data passing the normality test (Shapiro-Wilk). A Kruskal-Wallis multiple comparisons test was used to compare the means between groups of data with a non-normal distribution. 


\section{Supplementary Materials:}

Fig. S1. Blood biochemistry of Lassa virus (LASV) challenged cynomolgus monkeys

Fig. S2. LASV replication in cynomolgus monkeys infected with the heterologous lineages

Fig. S3. LASV replication in cynomolgus monkeys infected with the homologous lineage

Fig. S4. LASV replication in the organs of cynomolgus monkeys after LASV challenge

Fig. S5. LASV antigen is detected in the brains of control, but not of vaccinated, macaques

Table S1. Detection of vaccine RNA by RT-PCR for the cross-protection experiment

Table S2. Detection of vaccine RNA by RT-PCR for the long-term protection experiment

Table S3. Percentage amino acid homology between the NP and GPC proteins from strain Josiah (lineage IV) and strains representing other lineages.

Table S4. Scoring and endpoints for animal studies. 


\section{REFERENCES}

1. S. Bagcchi, Lassa fever outbreak continues across Nigeria. The Lancet Infectious Diseases 20, 543 (2020).

2. L. E. Kafetzopoulou et al., Metagenomic sequencing at the epicenter of the Nigeria 2018 Lassa fever outbreak. Science 363, 74-77 (2019).

3. E. J. Mateer, C. Huang, N. Y. Shehu, S. Paessler, Lassa fever-induced sensorineural hearing loss: A neglected public health and social burden. PLoS Negl Trop Dis 12, e0006187 (2018).

4. E. Fichet-Calvet, D. J. Rogers, Risk maps of Lassa fever in West Africa. PloS Negl. Trop. Dis. 3, e388 (2009).

5. K. Salami et al., Meeting report: WHO consultation on accelerating Lassa fever vaccine development in endemic countries, Dakar, 10-11 September 2019. Vaccine 38, 4135-4141 (2020).

6. S. L. M. Whitmer et al., New Lineage of Lassa Virus, Togo, 2016. Emerg Infect Dis 24, 599-602 (2018).

7. A. Yadouleton et al., Lassa fever in Benin: description of the 2014 and 2016 epidemics and genetic characterization of a new Lassa virus. Emerging Microbes \& Infections 9, 1761-1770 (2020).

8. M. D. Bowen et al., Genetic diversity among Lassa virus strains. J. Virol. 74, 6992-7004 (2000).

9. M. R. Wiley et al., Lassa virus circulating in Liberia: a retrospective genomic characterisation. The Lancet Infectious Diseases 19, 1371-1378 (2019).

10. M. Mateo et al., Vaccines inducing immunity to Lassa virus glycoprotein and nucleoprotein protect macaques after a single shot. Science Translational Medicine 11, eaaw3163 (2019).

11. F. Overbosch et al., Public health response to two imported, epidemiologically related cases of Lassa fever in the Netherlands (ex Sierra Leone), November 2019. Eurosurveillance 25, 2000265 (2020).

12. T. Wolf, R. Ellwanger, U. Goetsch, N. Wetzstein, R. Gottschalk, Fifty years of imported Lassa fever: a systematic review of primary and secondary cases. Journal of Travel Medicine 27, taaa035 (2020). 
13. K. Salami, D. Gouglas, C. Schmaljohn, M. Saville, N. Tornieporth, A review of Lassa fever vaccine candidates. Current Opinion in Virology 37, 105-111 (2019).

14. S. Baize et al., Early and strong immune responses are associated with control of viral replication and recovery in Lassa virus-infected cynomolgus monkeys. J. Virol. 83, 5890-5903 (2009).

15. J. ter Meulen et al., Old and New world arenaviruses share a highly conserved epitope in the fusion domain of the glycoprotein 2, which is recognized by Lassa virus-specific human CD4+ T-cell clones. Virology 321, 134-143 (2004).

16. J. ter Meulen et al., Characterization of human CD4+ T cell clones recognizing conserved and variable epitopes of the Lassa virus nucleoprotein. J. Virol. 74, 2186-2192 (2000).

17. R. W. Cross et al., Quadrivalent VesiculoVax vaccine protects nonhuman primates from viralinduced hemorrhagic fever and death. The Journal of Clinical Investigation 130, 539-551 (2020).

18. T. W. Geisbert et al., Development of a new vaccine for the prevention of Lassa fever. PLOS Med. 2, 537-545 (2005).

19. D. Safronetz et al., A Recombinant Vesicular Stomatitis Virus-Based Lassa Fever Vaccine Protects Guinea Pigs and Macaques against Challenge with Geographically and Genetically Distinct Lassa Viruses. PLoS Negl. Trop. Dis. 9, e0003736 (2015).

20. K. A. Cashman et al., A DNA vaccine delivered by dermal electroporation fully protects cynomolgus macaques against Lassa fever. Hum. Vacc. Immunother. 13, 2902-2911 (2017).

21. X. Carnec et al., Lassa virus nucleoprotein mutants generated by reverse genetics induce robust type I IFN response in human dendritic cells and macrophages. J. Virol. 85, 12093-12097 (2011).

22. M. D. Muhlebach, Vaccine platform recombinant measles virus. Virus Genes 53, 733-740 (2017).

23. K. Ramsauer et al., Immunogenicity, safety, and tolerability

of a recombinant measles-virus-based chikungunya vaccine: a randomised, double-blind, placebocontrolled, active-comparator, first-in-man trial. The Lancet Infectious Diseases 15, 519-527 (2015).

24. E. C. Reisinger et al., Immunogenicity, safety, and tolerability of the measles-vectored chikungunya virus vaccine MV-CHIK: a double-blind, randomised, placebo-controlled and active-controlled phase 2 trial. The Lancet 392, 2718-2727 (2019). 
25. S. Schrauf, R. Tschismarov, E. Tauber, K. Ramsauer, Current Efforts in the Development of Vaccines for the Prevention of Zika and Chikungunya Virus Infections. Frontiers in Immunology 11, 592 (2020).

26. D. U. Ehichioya et al., Phylogeography of Lassa Virus in Nigeria. Journal of Virology 93, e0092900919 (2019).

27. H. Haas et al., Immunogenicity and safety of intramuscular versus subcutaneous administration of a combined measles, mumps, rubella, and varicella vaccine to children 12 to 18 months of age. Human Vaccines \& Immunotherapeutics 15, 778-785 (2019).

28. S. Günther et al., Imported Lassa fever in Germany: molecular characterization of a new Lassa virus strain. Emerg. Infect. Dis. 6, 466-476 (2000).

29. M. Wolfl et al., Activation-induced expression of CD137 permits detection, isolation, and expansion of the full repertoire of $\mathrm{CD} 8+\mathrm{T}$ cells responding to antigen without requiring knowledge of epitope specificities. Blood 110, 201-210 (2007).

30. S. Jegaskanda, J. T. Weinfurter, T. C. Friedrich, S. J. Kent, Antibody-dependent cellular cytotoxicity is associated with control of pandemic H1N1 influenza virus infection of macaques. J Virol 87, 5512-5522 (2013).

31. M. Frentsch et al., Direct access to CD4+ T cells specific for defined antigens according to CD154 expression. Nature Med. 11, 1118-1124 (2005).

32. N. Sogoba, H. Feldmann, D. Safronetz, Lassa Fever in West Africa: Evidence for an Expanded Region of Endemicity. Zoonoses and Public Health 59, 43-47 (2012).

33. M. Mateo et al., Fatal Case of Lassa Fever, Bangolo District, Cote d'Ivoire, 2015. Emerg Infect Dis 25, 1753-1756 (2019).

34. D. Safronetz et al., A Recently Isolated Lassa Virus From Mali Demonstrates Atypical Clinical Disease Manifestations and Decreased Virulence in Cynomolgus Macaques. The Journal of Infectious Diseases 207, 1316-1327 (2013).

35. N. Baillet et al., Systemic viral spreading and defective host responses are associated with fatal Lassa fever in macaques. Communications Biology 4, 27 (2021).

36. J. R. Carrion et al., A ML29 reassortant virus protects guinea pigs against a distantly related Nigerian strain of Lassa virus and can provide sterilizing immunity. Vaccine 25, 4093-4102 (2007). 
37. D. R. Stein et al., A recombinant vesicular stomatitis-based Lassa fever vaccine elicits rapid and long-term protection from lethal Lassa virus infection in guinea pigs. NPJ vaccines 4, 8 (2019).

38. R. Stebbings et al., Immunogenicity of a Recombinant Measles-HIV-1 Clade B Candidate Vaccine. PLoS One 7, e50397 (2012).

39. R. Stebbings et al., Immunogenicity of a recombinant measles HIV-1 subtype $\mathrm{C}$ vaccine. Vaccine 31, 6079-6086 (2013).

40. S. Brandler et al., Measles Vaccine Expressing the Secreted Form of West Nile Virus Envelope Glycoprotein Induces Protective Immunity in Squirrel Monkeys, a New Model of West Nile Virus Infection. Journal of Infectious Diseases 206, 212-219 (2012).

41. J. Jiang et al., Immunogenicity of a protective intradermal DNA vaccine against lassa virus in cynomolgus macaques. Human Vaccines \& Immunotherapeutics 15, 2066-2074 (2019).

42. B. M. Sullivan et al., High crossreactivity of human T cell responses between Lassa virus lineages. PLOS Pathogens 16, e1008352 (2020).

43. S. Sakabe et al., Identification of Common CD8+ T Cell Epitopes from Lassa Fever Survivors in Nigeria and Sierra Leone. Journal of Virology 94, e00153-00120 (2020).

44. S. P. Fisher-Hoch, L. Hutwagner, B. Brown, J. B. McCormick, Effective vaccine for Lassa fever. J. Virol. 74, 6777-6783 (2000).

45. J. T. Manning, N. Forrester, S. Paessler, Lassa virus isolates from Mali and the Ivory Coast represent an emerging fifth lineage. Frontiers in Microbiology 6, 1037 (2015).

46. P. B. Jahrling, C. J. Peters, Serology and virulence diversity among Old-World arenaviruses, and the relevance to vaccine development. Med. Microbiol. Immunol. 175, 165-167 (1986).

47. P. K. Chattopadhyay, J. Yu, M. Roederer, Live-cell assay to detect antigen-specific CD4+ T-cell responses by CD154 expression. Nat. Protocols 1, 1-6 (2006).

48. J. ter Meulen, Lassa fever: implications of T-cell immunity for vaccine development. J. Biotech. 73, 207-212 (1999).

49. M. B. A. Oldstone et al., Common antiviral cytotoxic T-lymphocyte epitope for diverse arenaviruses. J. Virol. 75, 6273-6278 (2001). 
50. F. Amanat et al., Antibodies to the Glycoprotein GP2 Subunit Cross-React between Old and New World Arenaviruses. mSphere 3, e00189-00118 (2018).

51. T. Abreu-Mota et al., Non-neutralizing antibodies elicited by recombinant Lassa-Rabies vaccine are critical for protection against Lassa fever. Nature Communications 9, 4223 (2018).

52. K. A. Eberhardt et al., Ribavirin for the treatment of Lassa fever: A systematic review and metaanalysis. International Journal of Infectious Diseases 87, 15-20 (2019).

53. C. Lorin et al., Toxicology, biodistribution and shedding profile of a recombinant measles vaccine vector expressing HIV-1 antigens, in cynomolgus macaques. Naunyn-Schmiedeberg's Archives of Pharmacology 385, 1211-1225 (2012).

54. S. Baize et al., Lassa virus infection of dendritic cells and macrophages is productive but fails to activate cells. J. Immunol. 172, 2861-2869 (2004).

55. J. Schaeffer et al., Lassa virus activates myeloid dendritic cells but suppresses their ability to stimulate T cells. PLOS Pathogens 14, e1007430 (2018). 


\section{ACKNOWLEDGEMENTS}

We thank Pierrick Regnard (Silabe, Strasbourg) for medical care given to the monkeys. We thank S. Mundweiller, S. Godard, E. Moissonnier, D. Thomas, S. Mély, B. Labrosse, D. Pannetier, and C. Léculier (P4 Inserm - Jean Mérieux, US003, INSERM) for their assistance in conducting the BSL-4 experiments. We are grateful to G. Fourcaud and B. Lafoux (Institut Pasteur, CIRI, Lyon) for technical help with histological studies. We thank S. Becker for providing us with the Josiah strain and T.G. Ksiasek, P.E. Rollin, and P. Jahrling for the LASV monoclonal antibodies. We also thank Luis Branco (Zalgen Labs) for providing recombinant proteins. We are grateful to THEMIS Bioscience $\mathrm{GmbH}$, a wholly-owned subsidiary of Merck \& Co. Inc. (E. Tauber, A. Kort, K. Ramsauer, S. Schrauf, Y. Tomberger, and R. Tschismarov), to the Coalition for Epidemic Preparedness and Innovations (CEPI) (R. Hatchett, G. Thiry and M. Saville), and to C. Gerke (Department of Innovation Development, Institut Pasteur) for invaluable support.

\section{AUTHOR CONTRIBUTIONS}

MM and SB conceived the project. MM, SR, and SB designed the protocols. MM produced the MeV-NP vaccine. LF and PHM took care of the monkeys and performed the immunizations. MM, $\mathrm{SR}, \mathrm{AJ}, \mathrm{CG}, \mathrm{XC}, \mathrm{JH}, \mathrm{CP}, \mathrm{NB}, \mathrm{VBC}$ and OM performed the RNA extractions, PBMC isolation, and flow cytometry sample preparation. AV, SBar, OJ, OL, MD, and $A D$ took care of the monkeys and performed the LASV challenge, scoring, sampling, hematological and biochemical analyses, and necropsies. CC and HR supervised and validated the BSL-4 protocols. AJ, CG, MM, CP, and SR performed the ELISA. MM and AJ performed the ADCC assays. MM and SR performed the T cell reactivation assays. SR and SB performed the flow cytometry analyses. MM, SR, and AJ performed the RT-PCR and $\mathrm{qPCR}$ analyses. MM, SR, and CG performed the viral titrations and seroneutralization assays. JH prepared the samples for immunohistological analyses and analyzed them. GJ was involved in the setup of immunohistological analyses. MM and SB analyzed the data and wrote the paper, with the help of FT. SB supervised the project.

\section{FUNDING}


This study was entirely funded by a grant from the Coalition for Epidemic Preparedness and Innovations (CEPI-CfP-001) to SB.

\section{COMPETING INTERESTS}

The authors declare that they have no competing interests. MeV-NP is protected by U.S. patent Lassa vaccine no. 20200308555.

\section{DATA AVAILABILITY}

All data associated with this study are present in the paper or the Supplementary Materials. 


\section{FIGURE LEGENDS}

Figure 1. Outline of the experiments. (A) Scheme presenting the time of immunization, sampling, challenge, and necropsy for the four groups of the cross-protection study. Prime immunizations are indicated by blue arrows. Black arrows indicate sampling and purple arrows the time of challenge. Red arrows point to the day of necropsy and the number of animals euthanized is indicated. VB: MeV-NP immunization, Benin lineage VII challenge; VN: MeV-NP immunization, Nigeria lineage II challenge; CB: MeV immunization, Benin lineage VII challenge; $\mathrm{CN}$ : MeV immunization, Nigeria lineage II challenge. (B) Scheme presenting the time of immunization, sampling, challenge, and necropsy for the four groups of the long-term protection study. Prime immunizations are indicated by a blue arrow and boost immunizations are indicated by an orange arrow. Black arrows indicate sampling and purple arrows the time of challenge. Red arrows point to the day of necropsy and the number of monkeys euthanized is indicated. VJ-P: MeV-NP immunization, Josiah lineage IV challenge, prime only; VJ-PB: MeV-NP immunization, Josiah lineage IV challenge, prime-boost; CJ: VJ-P: MeV immunization, Josiah lineage IV challenge, prime-boost.

\section{Figure 2. Antibody responses induced after immunization of cynomolgus monkeys.}

(A) Detection of LASV-specific IgM against lineage IV (upper panel), lineage VII (middle panel) and lineage II (lower panel) in VB, CB, VN, and CN monkeys by ELISA. (B) Detection of LASV-specific IgG against lineage IV (upper panel), lineage VII (middle panel) and lineage II (lower panel) in VB, CB, VN, and CN monkeys by ELISA. (C) Detection of NP lineage IV (upper panel) and GP lineage IV-specific IgG in VB and VN monkeys by ELISA. (D) Detection of NP lineage II (upper panel) and GP lineage II-specific IgG in VB and VN monkeys by ELISA. For (A), (B), (C) and (D), each point represents the mean \pm SEM of three samples. (E) Detection of LASV-specific IgM against lineage IV in VJ-P, VJ-PB, and CJ monkeys by ELISA. (F) Detection of NP lineage IV, GP lineage IV, and LASV lineage IV IgG in VJ-P, VJ-PB, and CJ monkeys by ELISA. Each point represents the mean \pm SEM of four samples for VJ-P and VJ-PB, and three samples for the CJ controls. Statistical significance: ${ }^{\star} P \leq 0.05$, Mann-Whitney test. 
Figure 3. $\mathbf{T}$ cell responses induced after immunization of cynomolgus monkeys. (A and $B$ ) Quantification of $\mathrm{CD}^{+}(\mathbf{A})$ and $\mathrm{CD}^{+}(\mathbf{B})$ T cells specific for LASV GPC (upper graphs) and NP (lower graphs) peptides. The percentage of T cells producing TNF- $\alpha$ or IFN- $\gamma$ in response to peptide stimulation among total $\mathrm{CD}^{+}$or $\mathrm{CD}^{+} \mathrm{T}$ cells is presented according to the time after immunization after subtraction of the respective value measured for unstimulated $\mathrm{T}$ cells that represent the background T cell response. Each bar represents the mean \pm SEM of six monkeys for LASV Josiah-derived peptides and three monkeys for LASV Benin- and LASV Nigeria-derived peptides. The dashed lines represent the percentage of T cells from control monkeys producing cytokines in response to LASV peptides before challenge (mean of 10 samples) (C) Pie-chart representation of the proportion of each subpopulation of cytokine-positive $\mathrm{CD}^{+}$and $\mathrm{CD}^{+} \mathrm{T}^{-}$ cells responding to GPC or NP stimulation. (D) Quantification of CD8 ${ }^{+}$(upper graphs) and CD4 ${ }^{+}$ (lower graphs) T cells specific for LASV GPC peptides in primed monkeys (left graphs) or primedboosted monkeys (right graphs). (E) Quantification of $\mathrm{CD}^{+}$(upper graphs) and $\mathrm{CD}^{+}$(lower graphs) T cells specific for LASV NP peptides in primed monkeys (left graphs) or primed-boosted monkeys (right graphs). For (C) and (D), the percentage of T cells producing TNF- $\alpha$ or IFN- $\gamma$ in response to peptide stimulation among total $\mathrm{CD}^{+}$or $\mathrm{CD}^{+} \mathrm{T}$ cells is presented according to the time after immunization after subtraction of the respective value measured for unstimulated $\mathrm{T}$ cells. Each bar represents the mean \pm SEM of eight samples. Statistical significance: ${ }^{\star} P \leq 0.05,{ }^{* \star} P$ $\leq 0.01$, one-way ANOVA. The dashed lines represent the percentage of $\mathrm{T}$ cells from control monkeys producing cytokines in response to LASV peptides before challenge (mean of 8 samples) (F) Pie-chart representation of the proportion of each subpopulation of cytokine-positive CD8 ${ }^{+}$ and $\mathrm{CD}^{+}{ }^{+} \mathrm{T}$ cells responding to GPC or NP stimulation. (G to I) LASV-specific T cell responses were evaluated in PBMCs isolated from immunized monkeys at 317 days post immunization. The proportion of $\mathrm{GrzB}$ or perforin-expressing $\mathrm{CD} 8^{+}$and $\mathrm{CD} 4^{+} \mathrm{T}$ cells (G), CD137-expressing $\mathrm{CD} 8^{+}$and $\mathrm{CD}^{+}{ }^{+}$cells $(\mathbf{H})$ or HLA-DR-expressing CD4 ${ }^{+} \mathrm{T}$ cells (I) in response to LASV Josiah GPC- and NPderived peptides is shown. Data are presented as the percentage of cells expressing the indicated marker in response to peptide stimulation minus the percentage of expressing cells in response to mock stimulation for CJ (grey bars), VJ-P (red bars), and VJ-PB (blue bars). Each bar represents 
the mean \pm SEM of three (CJ) or four samples (VJ-P, VJ-PB) of PBMCs obtained 317 days after immunization.

Figure 4. Clinical monitoring of immunized monkeys after a LASV challenge. (A) Clinical scores of individual monkeys from groups $V B, C B, V N$, and $C N$ after challenge with LASV Benin (VB and CB) or LASV Nigeria (VN and CN) in the cross-protection experiment. (B) Monitoring of body temperature by rectal measurement during the course of LASV Benin and LASV Nigeria infections. Individual data are presented for each monkey. (C) Clinical scores of individual monkeys from groups VJ-P, VJ-PB, and CJ after the challenge with LASV Josiah in the long-term experiment. (D) Monitoring of body temperature by real-time measurement during the course of LASV Josiah infection. Individual data are presented for each monkey. (E) Analysis of biological parameters during the course of LASV infection. Each point represents the mean \pm SEM of three (VB, VN, CB, CN, CJ) or four samples (VJ-P, VJ-PB) for the ALT, AST, and CRP concentrations, except for individualized points representing the values of one monkey. For statistical purposes, data collected from monkeys euthanized on day 14 were compared to data collected on day 15 for the other monkeys and data collected at the end of the experiment (day 28 to 30) were compared with each other. (F) ALT (upper panel) and AST (lower panels) concentrations in control monkeys at day 12 post challenge. Statistical significance: ${ }^{*} P \leq 0.05,{ }^{*} P \leq 0.01,{ }^{* \star \star *} P \leq 0.0001$, one-way ANOVA.

Figure 5. LASV replication in cynomolgus monkeys. (A) Quantification (in FFU per milliliter) of LASV infectious particles in plasma (top), nasal swabs (middle), or oral swabs (bottom) according to the time after challenge with LASV Benin (VB and CB) or LASV Nigeria (VN and CN) in the crossprotection study. (B) Quantification (in FFU per milliliter) of LASV infectious particles in plasma (top), nasal swabs (middle), or oral swabs (bottom) according to the time after challenge with LASV Josiah in the long-term experiment. (C) Quantification of viral load by RT-qPCR in the plasma (top), nasal swabs (middle), or oral swabs (bottom) according to the time after challenge with LASV Benin (VB and CB) or LASV Nigeria (VN and CN) in the cross-protection study. (D) Quantification of viral load by RT-qPCR in the plasma (top), nasal swabs (middle), or oral swabs (bottom) according to the time after challenge LASV Josiah in the long-term experiment. Each point represents the mean $\pm \mathrm{SEM}$ of three $(\mathrm{VB}, \mathrm{VN}, \mathrm{CB}, \mathrm{CN}, \mathrm{CJ})$ or four samples (VJ-P, VJ-PB), 
except for individualized points representing the values of one monkey. For statistical purposes, data collected from monkeys euthanized on day 14 were compared to data collected on day 15 for the other monkeys and data collected at the end of the experiment (day 28 to 30 ) were compared with each other. Statistical significance: ${ }^{\star} P \leq 0.05,{ }^{* *} P \leq 0.01,{ }^{* \star * P} P \leq 0.001$, ${ }^{\star * * * P} \leq$ 0.0001. For panel A and C, an unpaired t test or a Mann-Whitney test were performed after testing normality. For panel B and D, a one-way ANOVA or a Kruskal-Wallis test were performed after testing normality.

Figure 6. Analysis of the antibody responses induced after LASV infection. (A) Detection of post challenge LASV lineage-specific IgG in VB, VN, CB and CN monkeys by ELISA. Each point represents the mean \pm SEM of three samples except for control monkeys at day 15 or later. Individual points represent the value of one monkey. Statistical significance: ${ }^{*} P \leq 0.05$, KruskalWallis test. (B) Detection of post-challenge NP lineage IV and GPC lineage IV-specific IgG in VB, VN, CB and CN monkeys by ELISA. Each point represents the mean \pm SEM of three samples except for control monkeys at day 15 (2 monkeys). (C) Detection of post challenge LASV lineage-specific IgG in CJ, VJ-P and VJ-PB monkeys by ELISA. Each point represents the mean \pm SEM of four (VJ-P and VJ-PB) or three samples (CJ). (D) Detection of post-challenge NP lineage IV and GPC lineage IV IgG in CJ, VJ-P and VJ-PB monkeys by ELISA. Each point represents the mean \pm SEM of three samples except for control monkeys at day 15 (2 monkeys). Statistical significance: ${ }^{\star} P \leq 0.05$, Kruskal-Wallis test. The red asterisks indicate differences between VJ-P and CJ, the blue asterisks between VJ-PB and CJ. (E and F) Quantification of NAbs in the plasma according to the time after LASV infection in monkeys of the cross-protection study (E) and monkeys of the long-term study (F). Individual data of the monkeys represent the highest dilution of plasma showing more than 50\% neutralizing activity. ( $\mathbf{G}$ and $\mathbf{H}$ ) Analysis of antibody-dependent cell cytotoxicity induced by immunoglobulins after challenge in monkeys of the cross-protection study (G) and of the longterm study $(\mathbf{H})$. Results are expressed as the percentage of NK cells (defined as CD3- CD20- CD8 ${ }^{+}$ cells among PBMC as previously described (35)) expressing CD107a after culture in the presence of $C B, C N, V B, V N, C J, V J-P$, and VJ-PB plasma in Josiah LASV GPC-coated microplates minus the percentage of CD107a-expressing NK cells when culture was performed with the same plasma in Ebola virus GPC-coated microplates, as negative antigen. For statistical purposes, data collected 
from monkeys euthanized on day 12 or 14 were compared to data collected on day 15 for the other monkeys and data collected at the end of the experiment (day 28 to 30) were compared with each other. A t-test was used to compare control and immunized monkeys for lineage II and VII at 0,6 , and 15 days post infection and to compare VN and VB (G). Statistical significance $(P \leq$ 0.05) was indicated with a black asterisk and the compared groups of monkeys indicated above (H). A one-way ANOVA test was used for day 0, 6, and 15 to compare CJ, VJ-P, and VJ-PB at each timepoint and a t test was used to compare only VJ-P and VJ-PB at day 28 , and a significant difference $(P \leq 0.05)$ between $C J$ and VJ-P is indicated with black asterisks $(H)$.

Figure 7. $T$ cell responses induced in cynomolgus monkeys challenged one month after immunization. (A to D) Quantification of the proportion of $\mathrm{CD}^{+}(\mathbf{A})$ and $\mathrm{CD}^{+}(\mathbf{B}) \mathrm{T}$ cells specific for LASV GPC peptides derived from Josiah LASV or of $\mathrm{CD}^{+}(\mathbf{C})$ and $\mathrm{CD}^{+}(\mathbf{D}) \mathrm{T}$ cells specific for LASV GPC peptides derived from Benin or Nigeria LASV. (E and F) Quantification of CD8 ${ }^{+} \mathrm{T}$ cells specific for LASV NP peptides derived from Josiah LASV (E) or Benin or Nigeria LASV (F). The percentage of T cells producing TNF- $\alpha$ or IFN- $\gamma$ in response to peptide stimulation among total $\mathrm{CD}^{+} \mathrm{T}$ cells is presented according to the time after challenge after subtraction of the respective value measured for unstimulated T cells. Each bar represents the mean \pm SEM of six samples for Josiah LASV and three samples for Benin and Nigeria LASV. The proportion of each subpopulation of cytokine-positive T cells is presented in the pie charts. An unpaired $t$ test or a Mann-Whitney test were performed after testing normality to compare Benin LASV- or Nigeria LASV-infected monkeys.

Figure 8. $T$ cell responses induced in cynomolgus monkeys challenged one year after immunization. (A and B) Quantification of $\mathrm{CD} 8^{+} \mathrm{T}$ cells specific for LASV GPC (A) or NP (B) peptides derived from Josiah strain. (C and D) Quantification of $C D 4^{+} T$ cells specific for LASV GPC (C) or NP (D) peptides derived from the Josiah strain. The percentage of T cells producing TNF- $\alpha$ or IFN- $\gamma$ in response to peptide stimulation among total $\mathrm{CD} 8^{+} \mathrm{T}$ cells is presented according to the time after challenge after subtraction of the respective value measured for unstimulated $T$ cells. Each bar represents the mean \pm SEM of eight samples. The proportion of each subpopulation of cytokine-positive T cells is presented in the pie charts. Statistical significance: ${ }^{\star} P \leq 0.05$, oneway ANOVA. (E and $\mathbf{F}$ ) Percentage of $\mathrm{CD}^{+} \mathrm{T}$ cells expressing CD154 in response to stimulation 
with Josiah GPC (E) or Josiah NP (F) peptides according to the time after challenge. A one-way ANOVA test was used. 


\section{Figure 1}

A

Cross-protection schedule

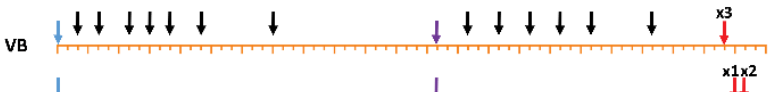

VN

CB

CN $\begin{array}{lllllllllllllllll}1 \\ 0\end{array}$ Days post immunization

B

$\downarrow$ immunization $\downarrow$ sampling $\downarrow$ challenge $\downarrow$ necropsy

Long-term post immunization schedule

Prime Boost

Challenge

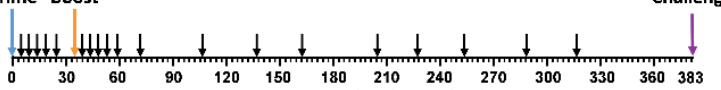

Long-term post challenge schedule

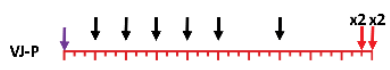

VJ-PB

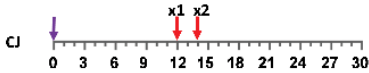

Days post challenge 


\section{Figure 2}

A
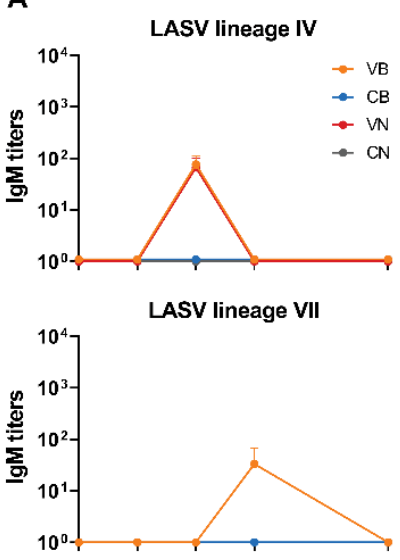

LASV lineage II

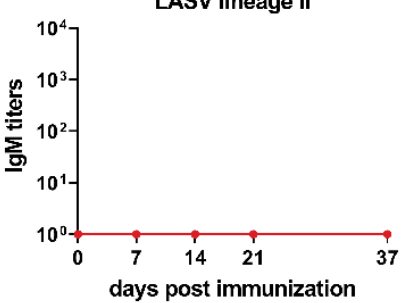

days post immunization

F

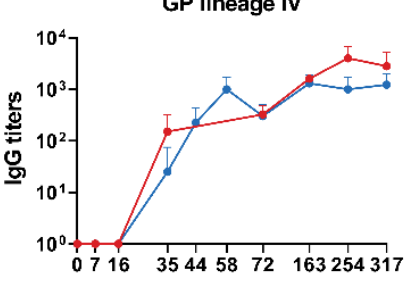

B

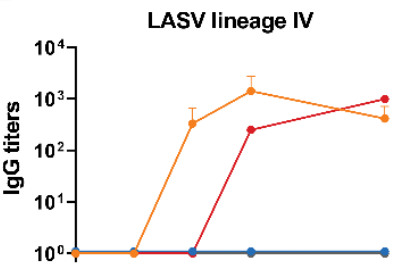

LASV lineage VII

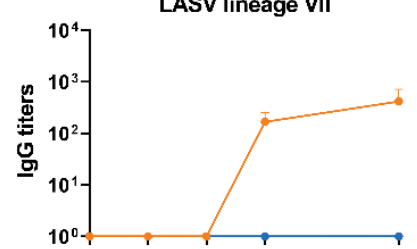

LASV lineage II
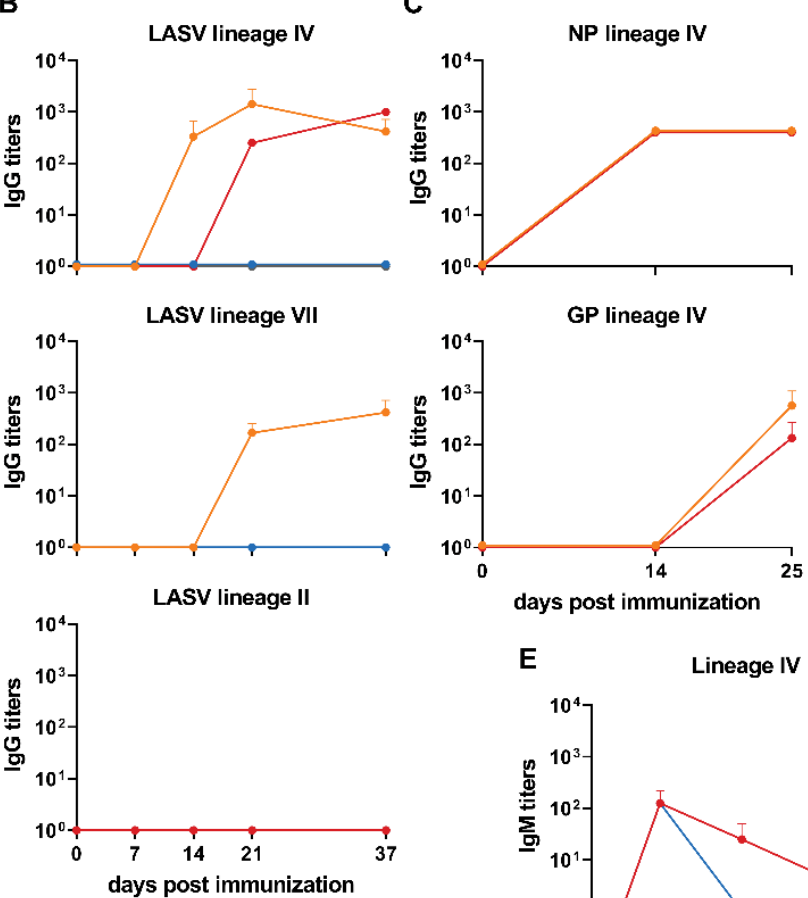

GP lineage IV

days post immunization

E

D

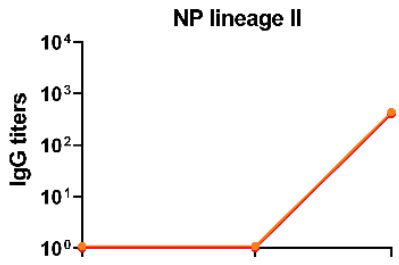

GP lineage II

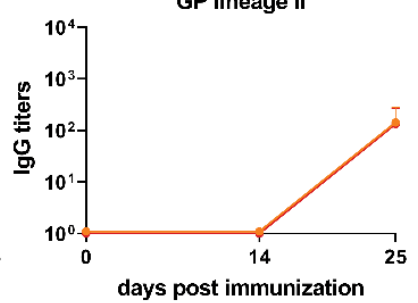

Lineage IV

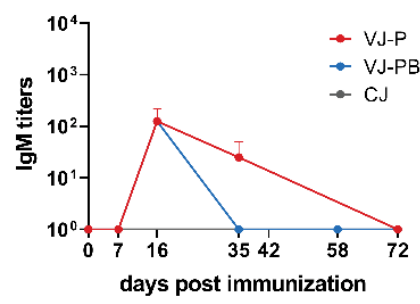

NP lineage IV

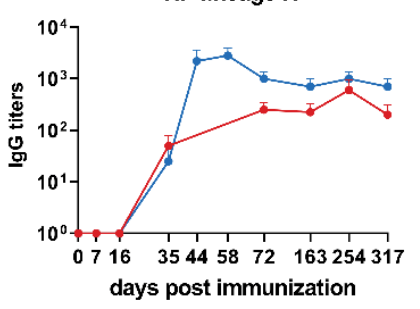

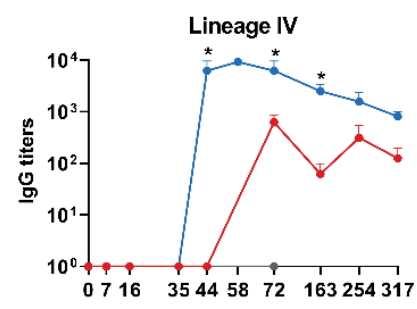




\section{Figure 3}
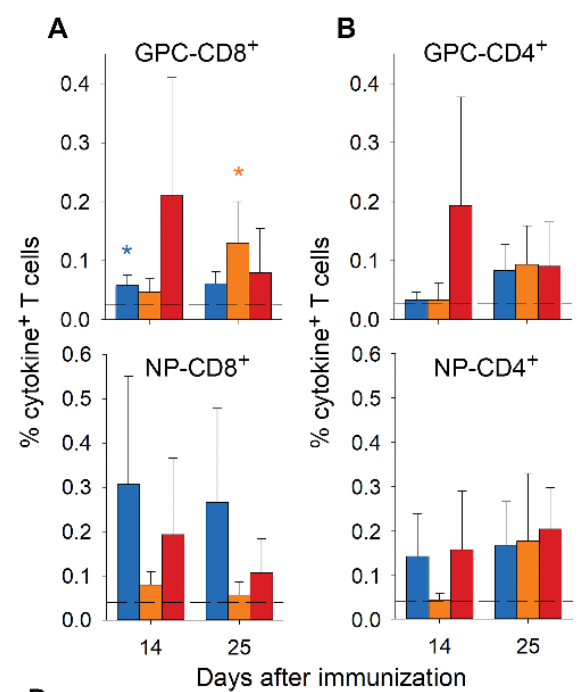

C

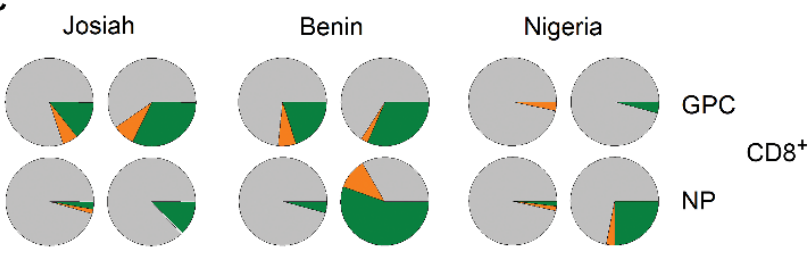

D
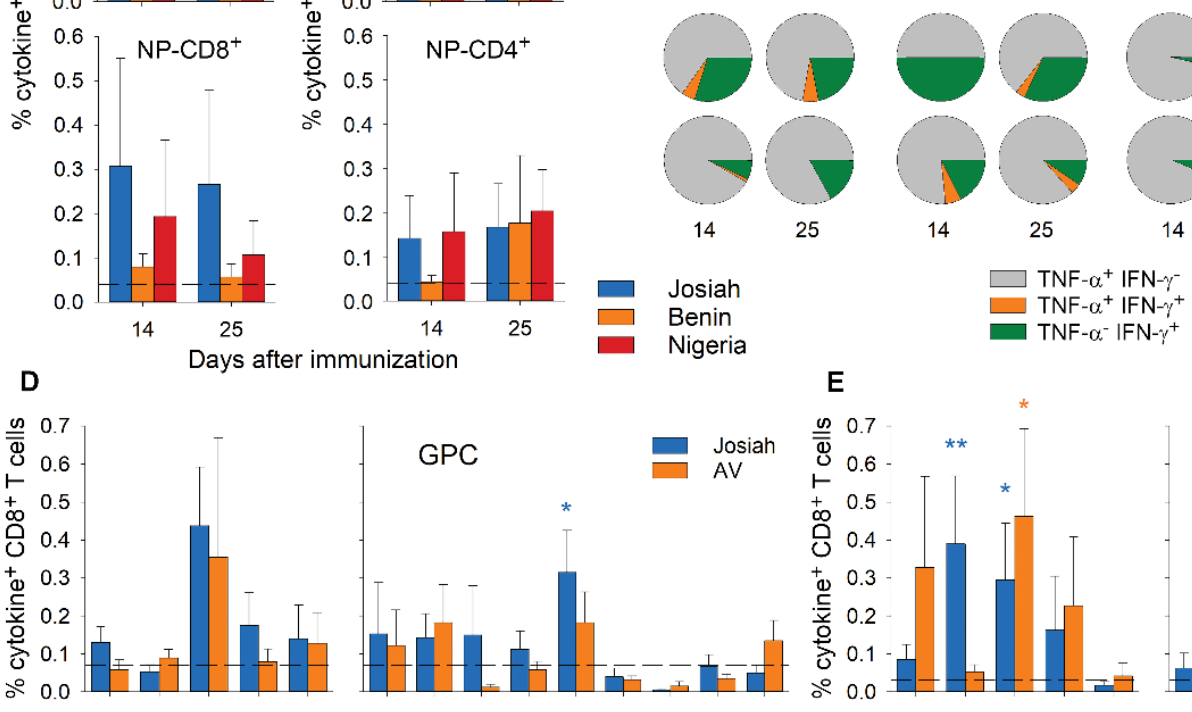

E
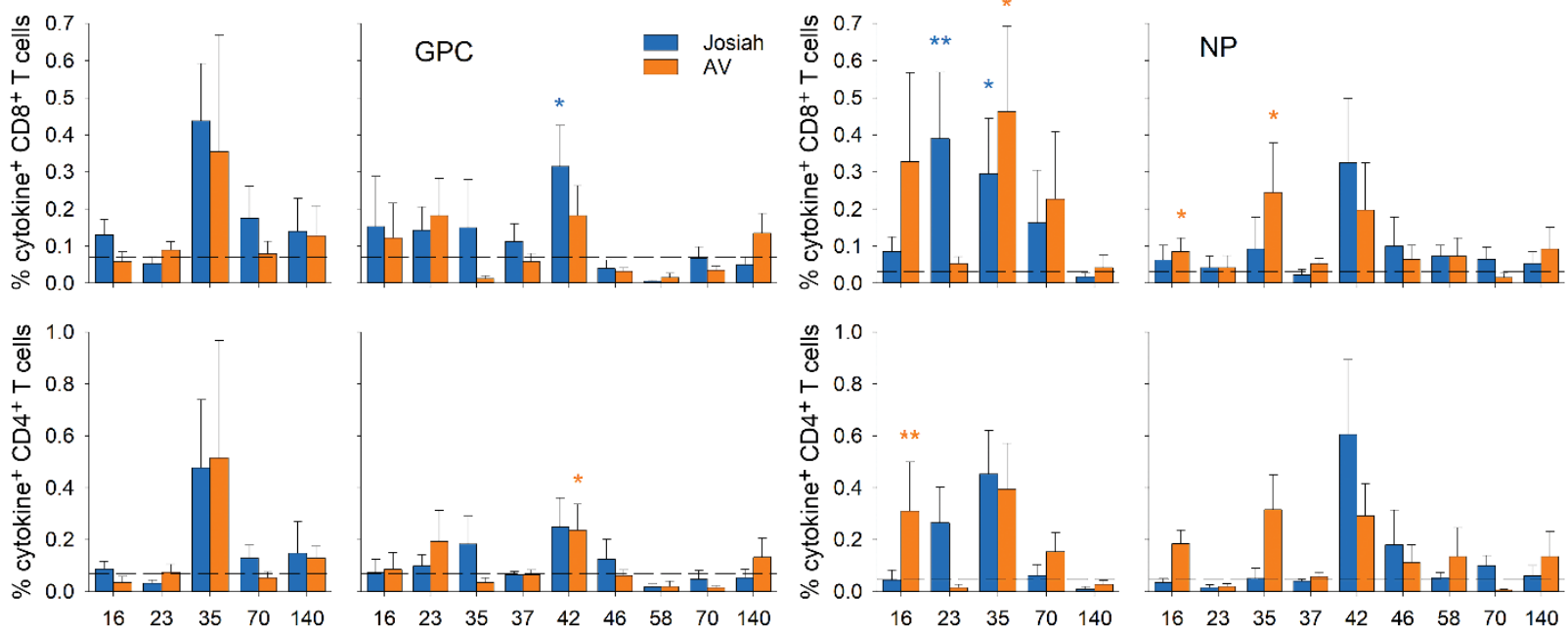
Days after immunization

F

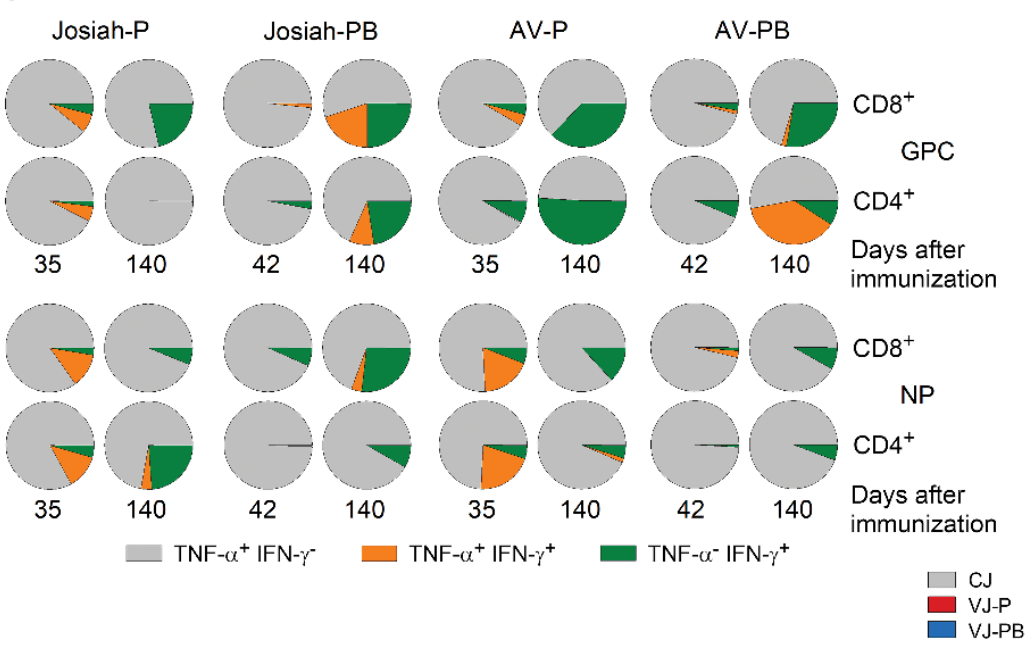

G
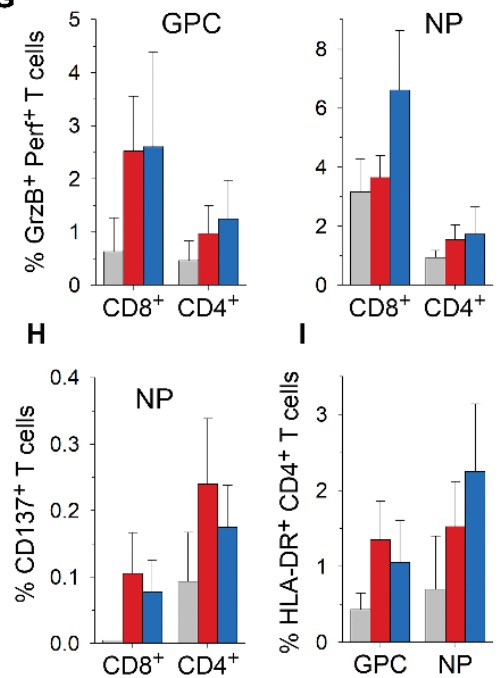


\section{Figure 4}

A
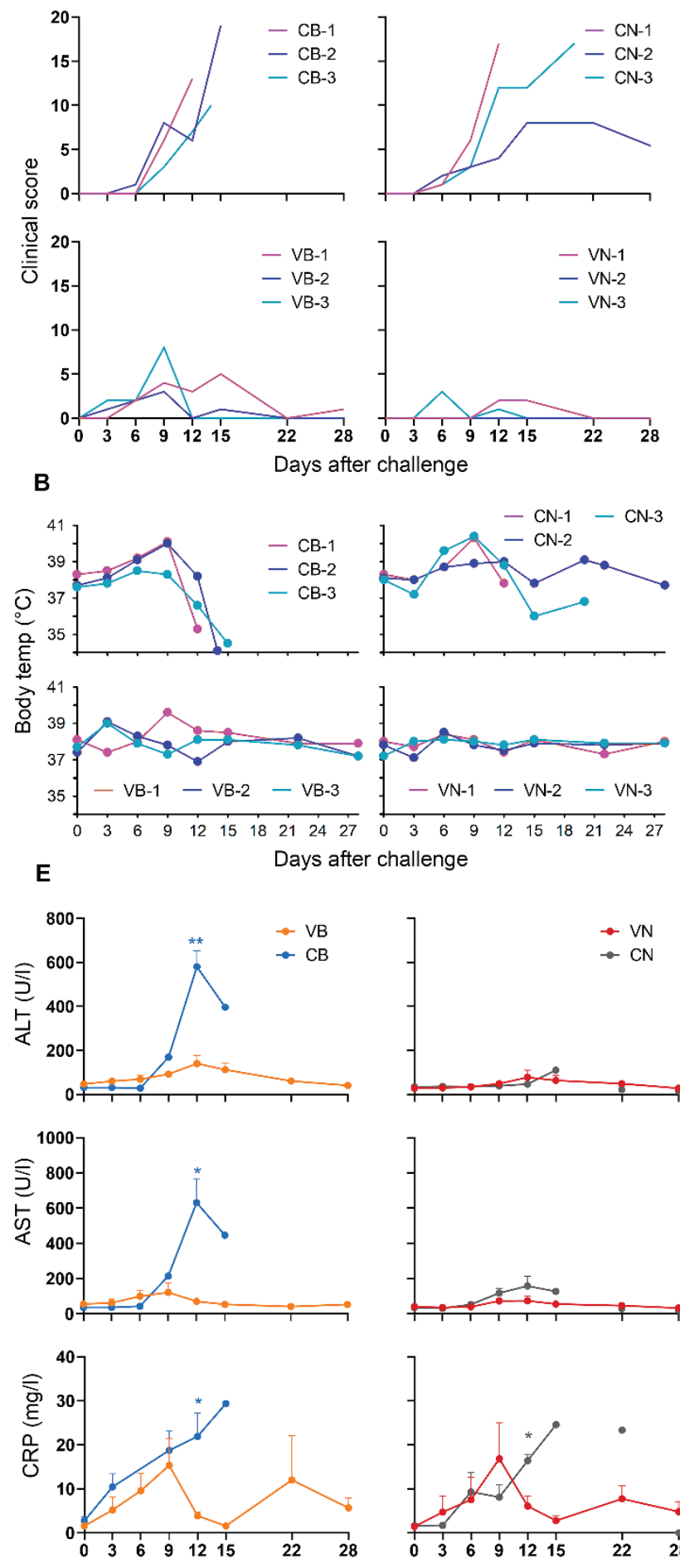

C
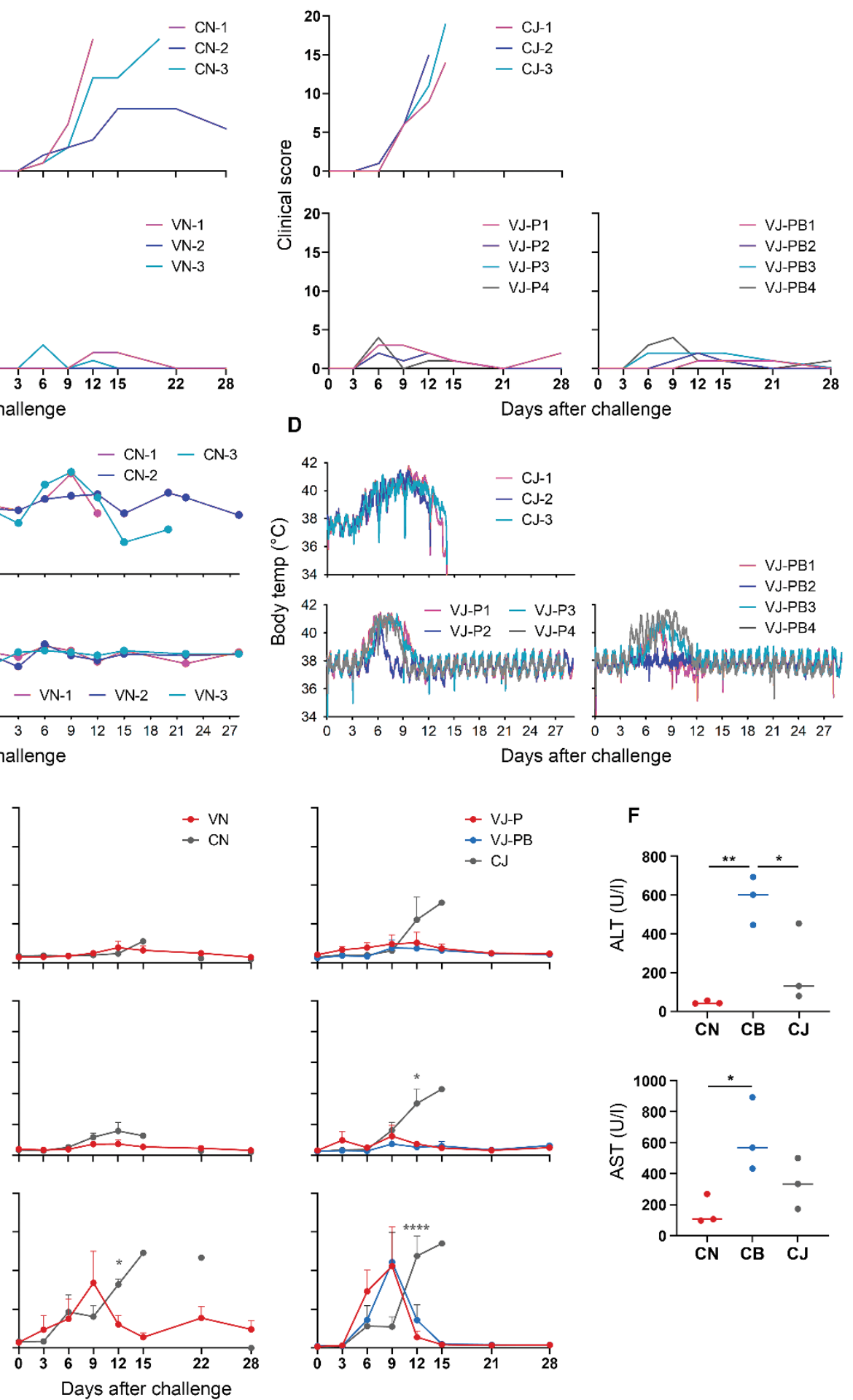


\section{Figure 5}

A
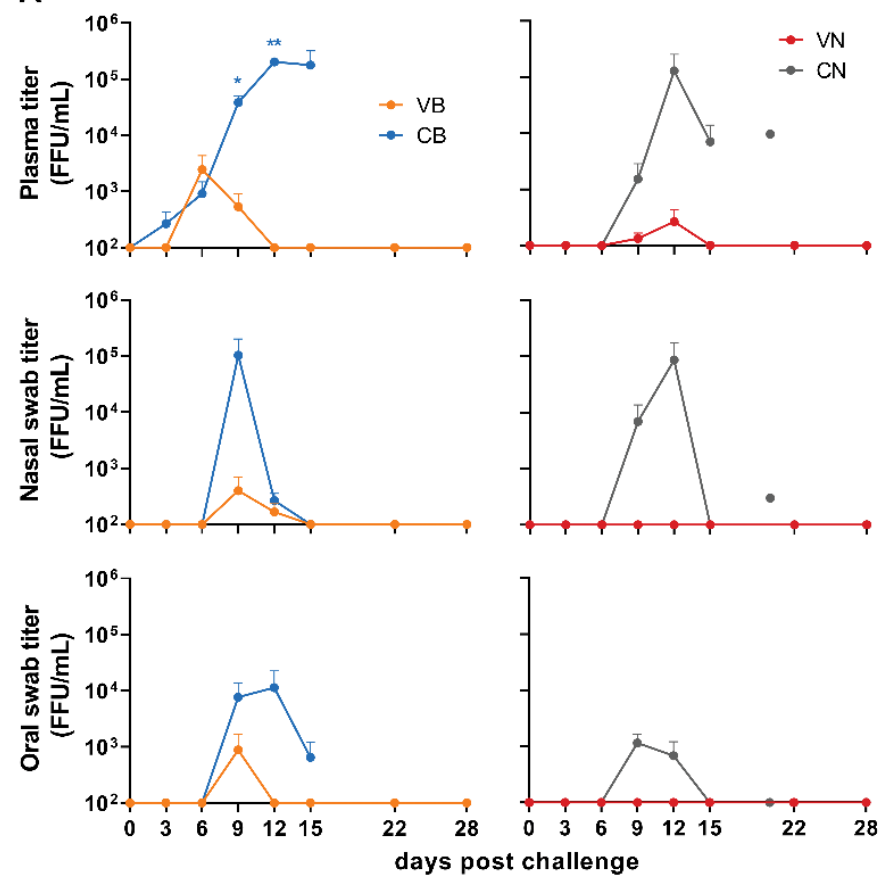

C
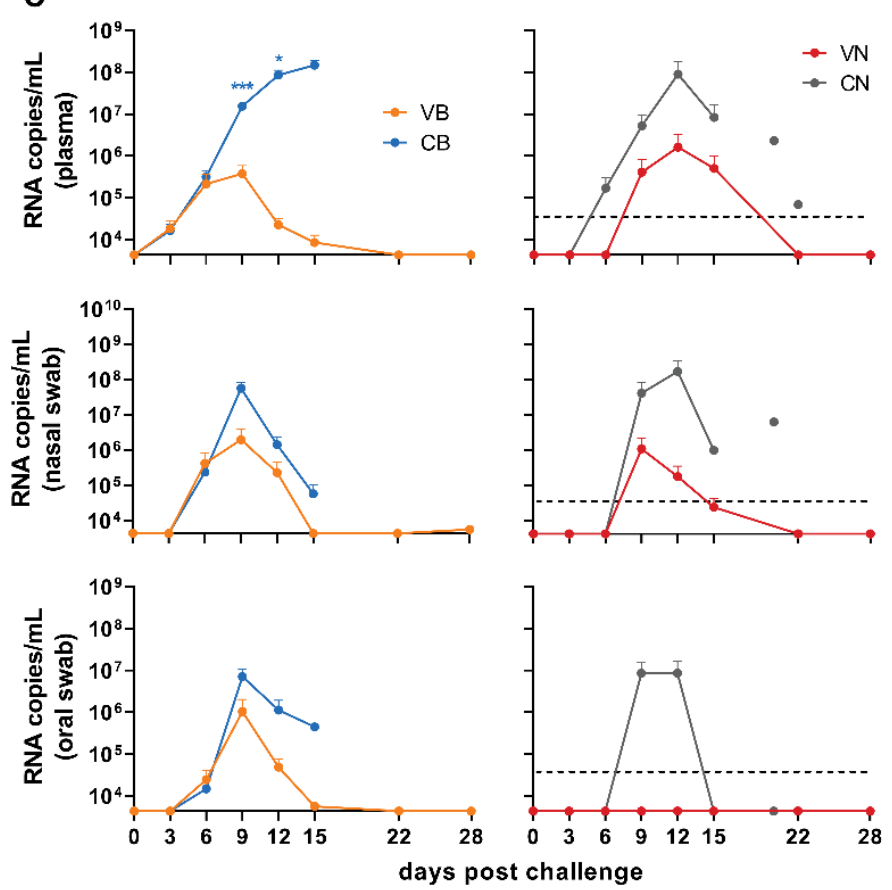

B
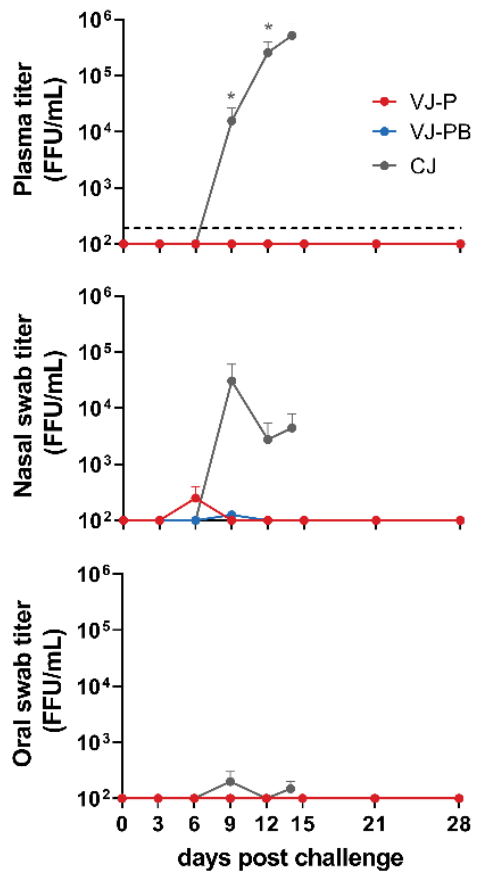

D
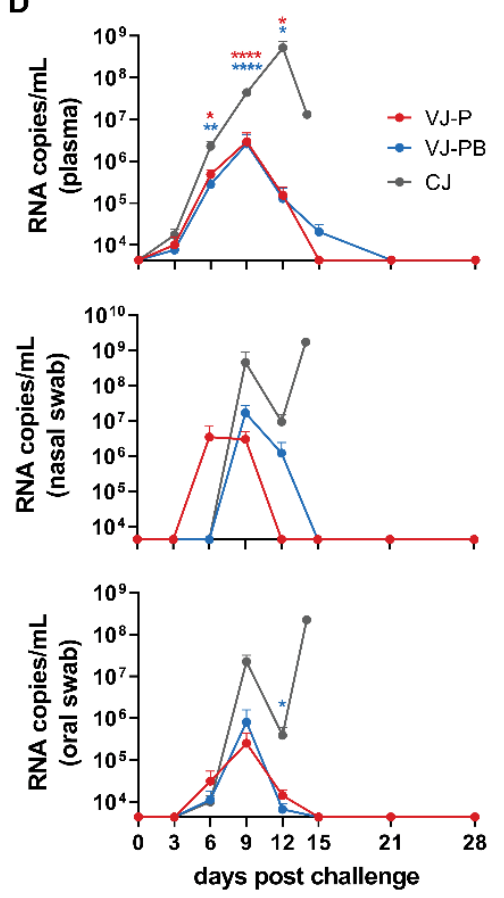


\section{Figure 6}
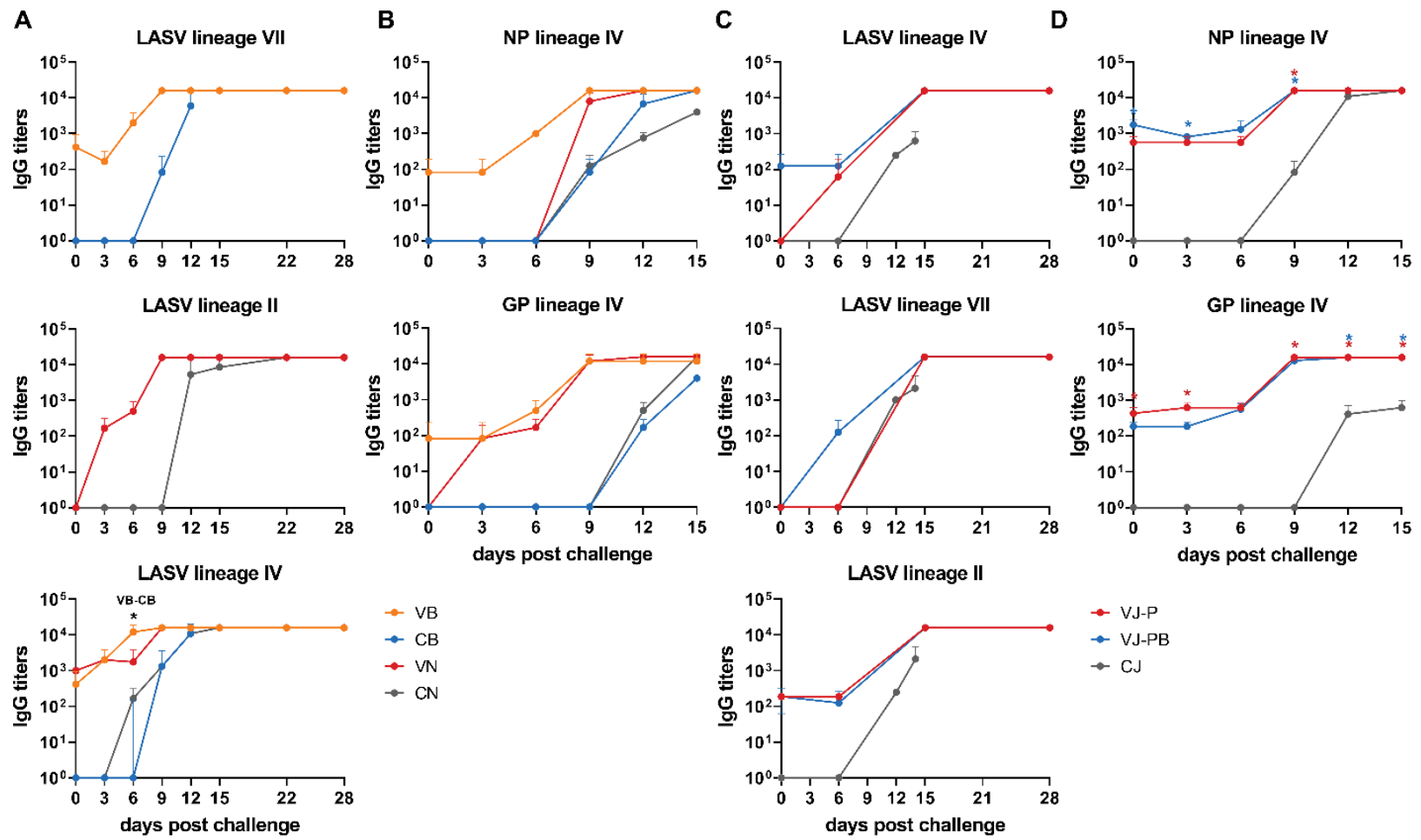

$\rightarrow V B$

$\rightarrow$ CB

$\rightarrow$ VN

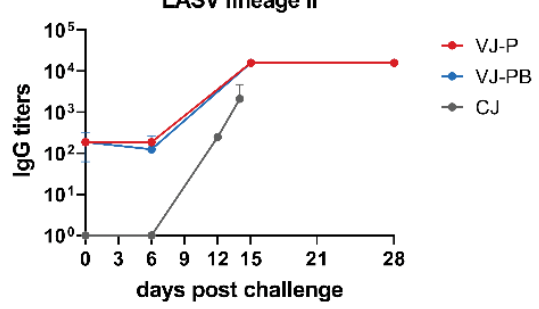

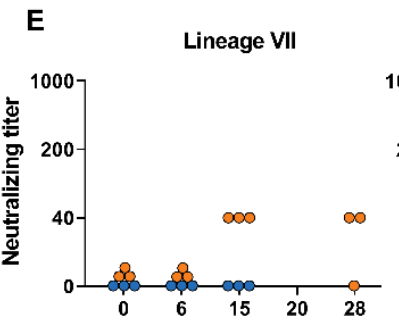

G

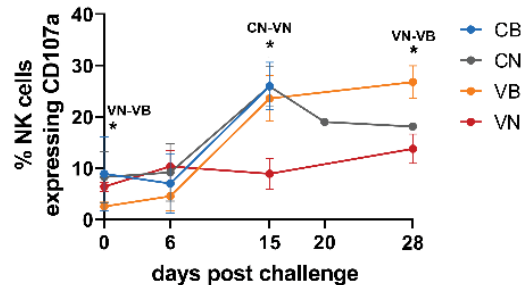

F

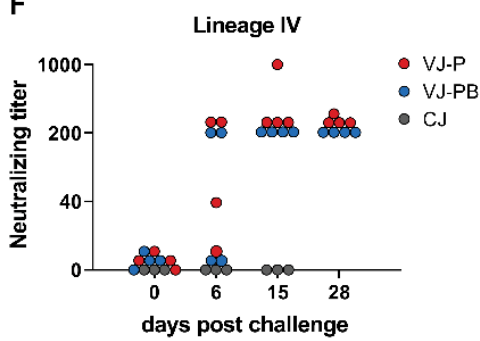

H

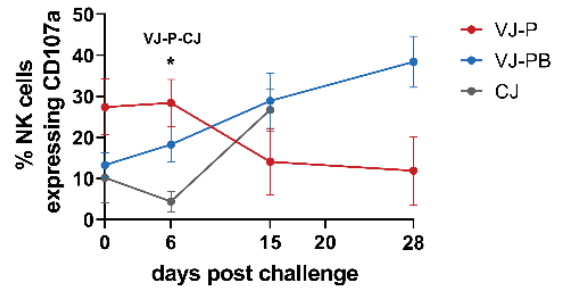


Figure 7

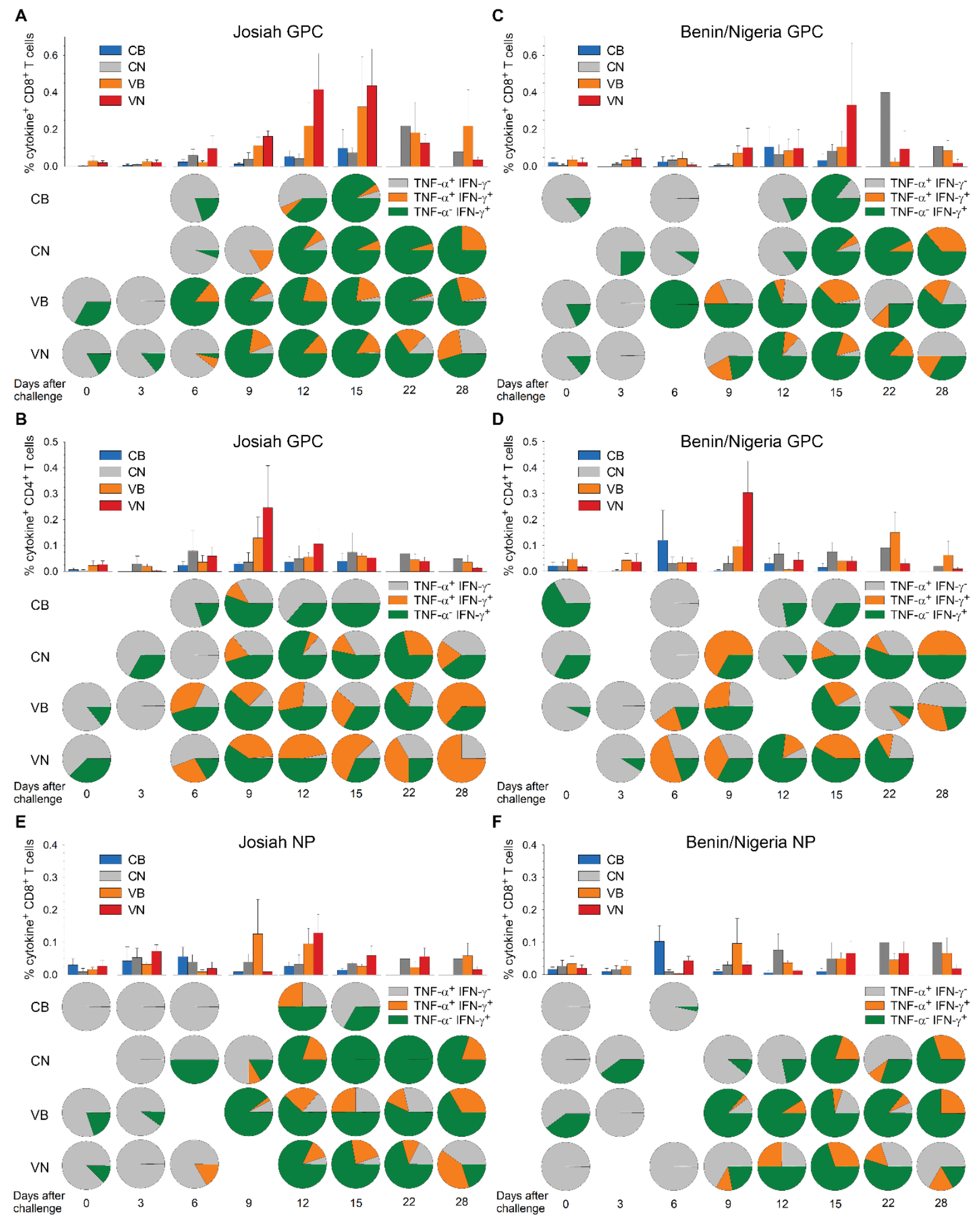


Figure 8

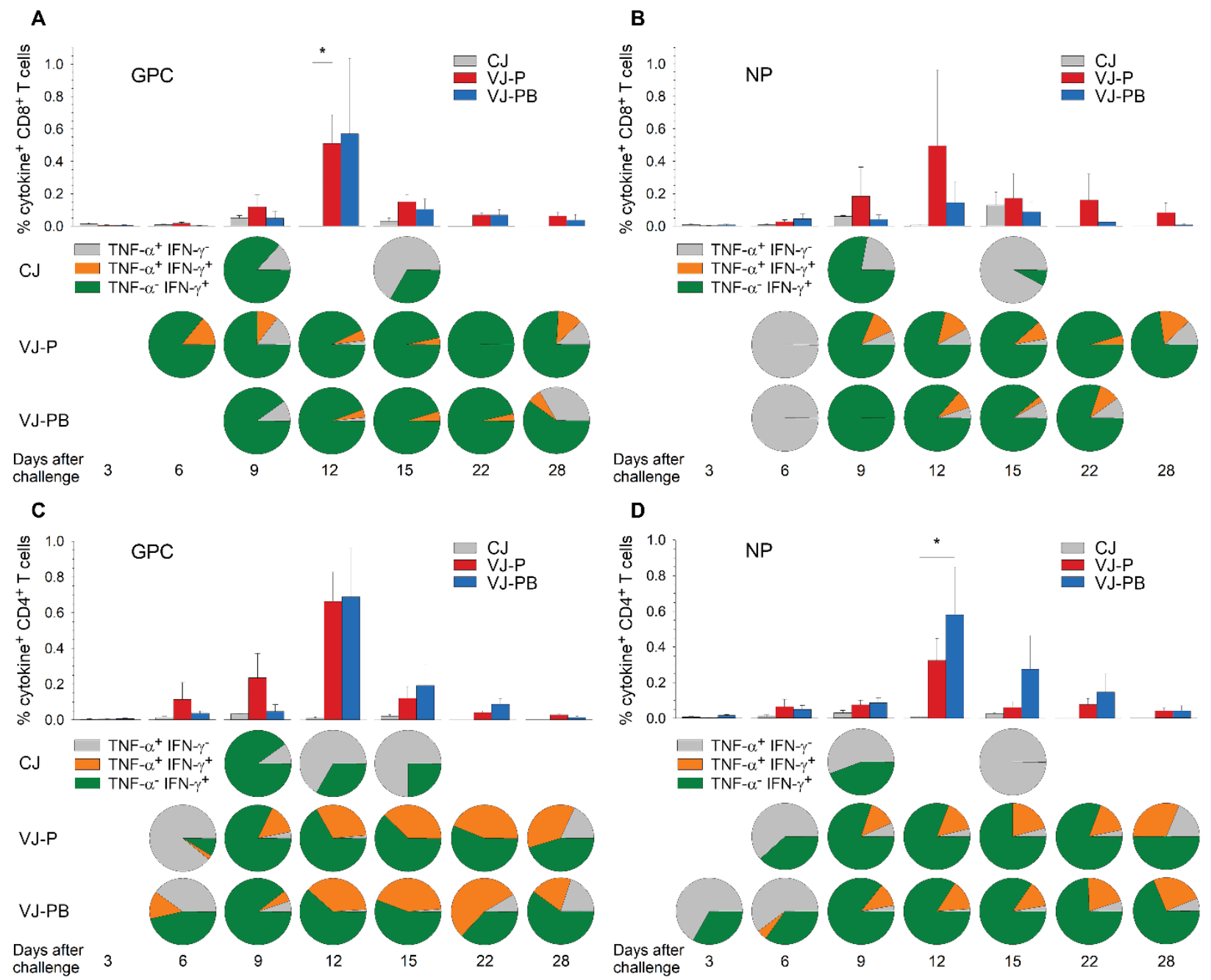

E

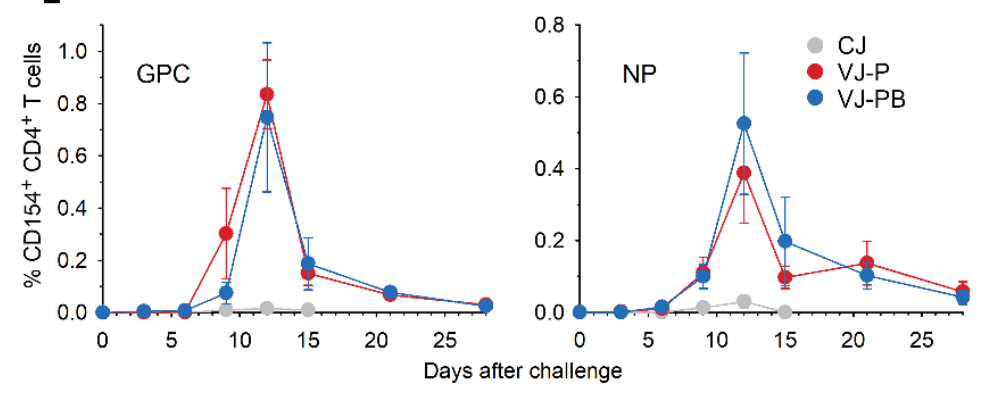



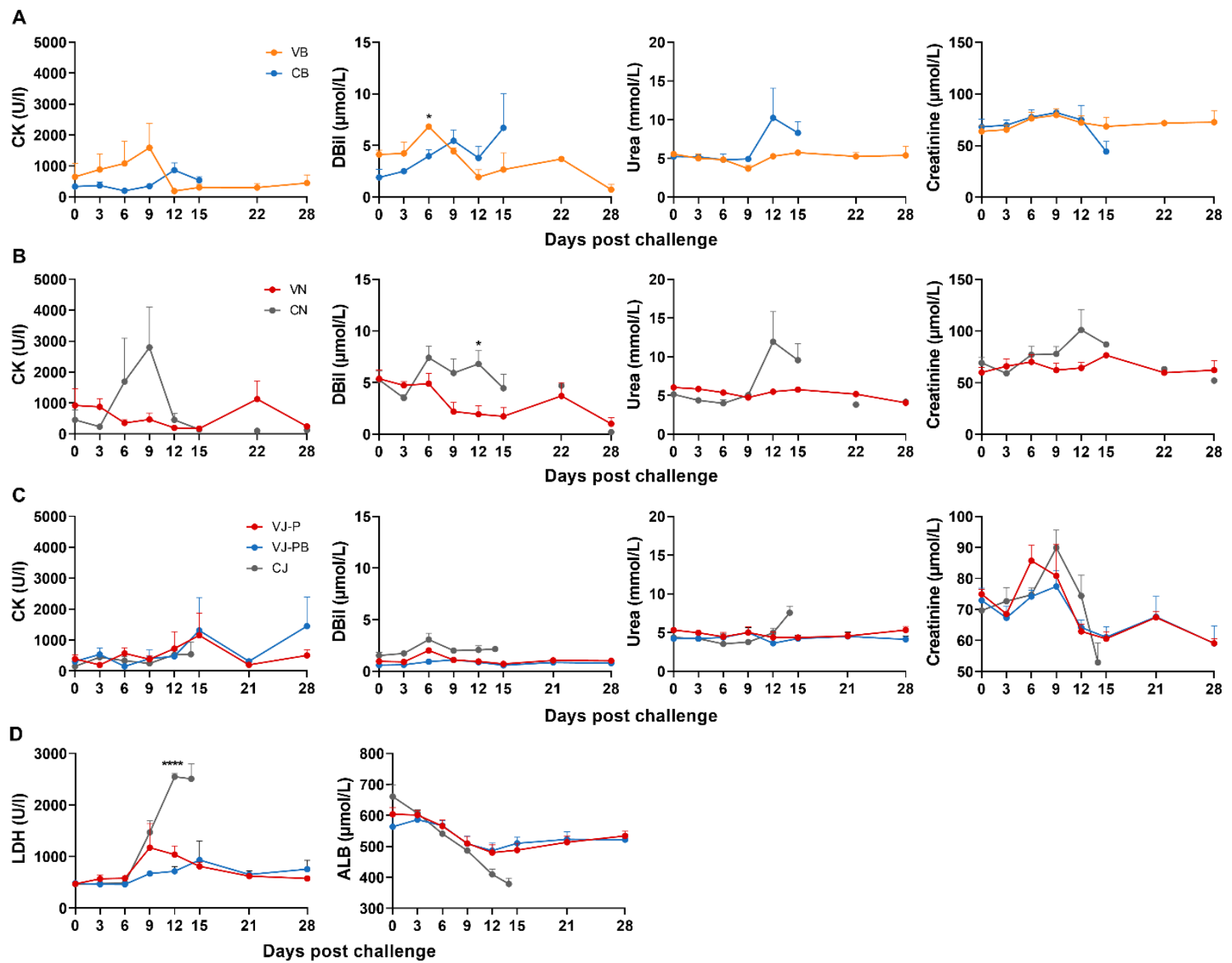

Fig. S1. Blood biochemistry of Lassa virus (LASV) challenged cynomolgus monkeys. (A to C)

The concentrations of creatine kinase (CK), direct bilirubin (DBil), urea, and creatinine were quantified in the plasma of VB and CB animals after challenge with LASV lineage VII (A), VN and $\mathrm{CN}$ animals after challenge with LASV lineage II (B) for the cross-protection experiment, and VJ-P, $\mathrm{VJ}-\mathrm{PB}$, and $\mathrm{CJ}$ animals after challenge with LASV lineage IV for the long-term protection experiment (C). (D) The plasma concentrations of lactate dehydrogenase (LDH) and albumin (ALB) were also measured after challenge for VJ-P and VJ-PB animals for the long-term experiment. Each point represents the mean $\pm \mathrm{SEM}$ of three $(\mathrm{VB}, \mathrm{VN}, \mathrm{CB}, \mathrm{CN}, \mathrm{CJ})$ or four samples (VJ-P, VJ-PB), except for individualized points representing the values of one animal. For statistical purposes, data collected from animals euthanized on day 14 were compared to data collected on day 15 for the other animals and data collected at the end of the experiment (day 28 to 30) were compared with each other. Statistical significance: ${ }^{\star} P \leq 0.05,{ }^{* \star \star \star} P \leq 0.0001$, one-way ANOVA. 
A
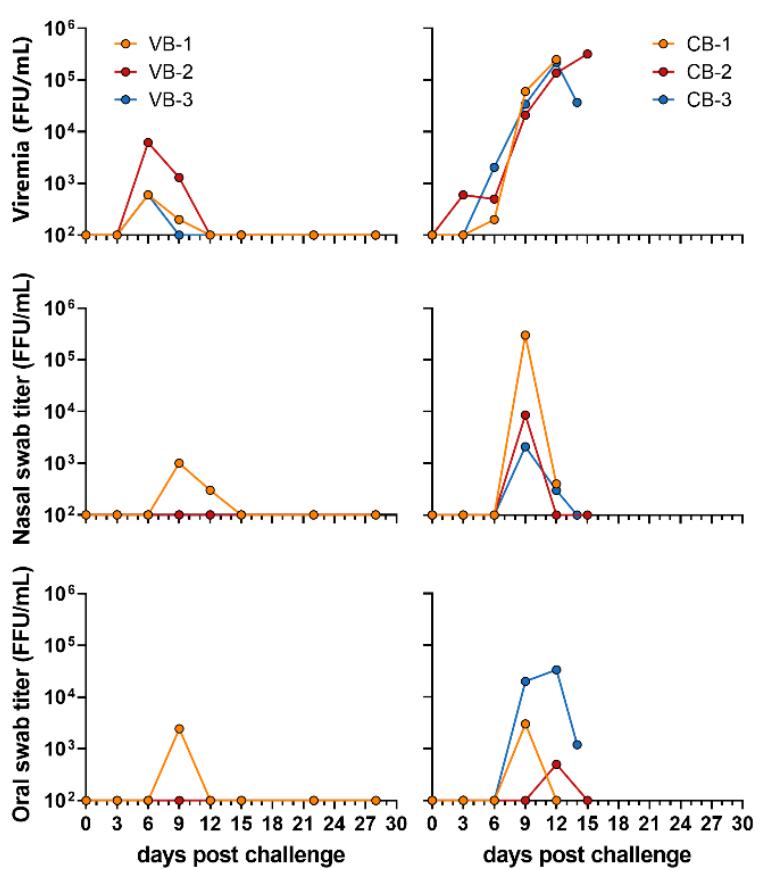

C
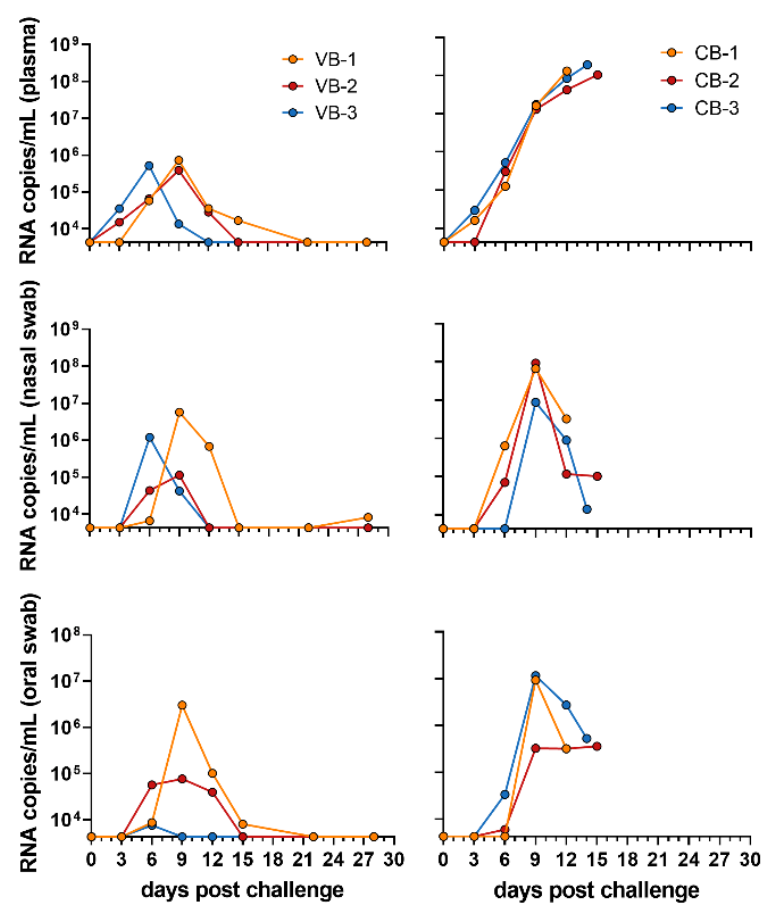

B
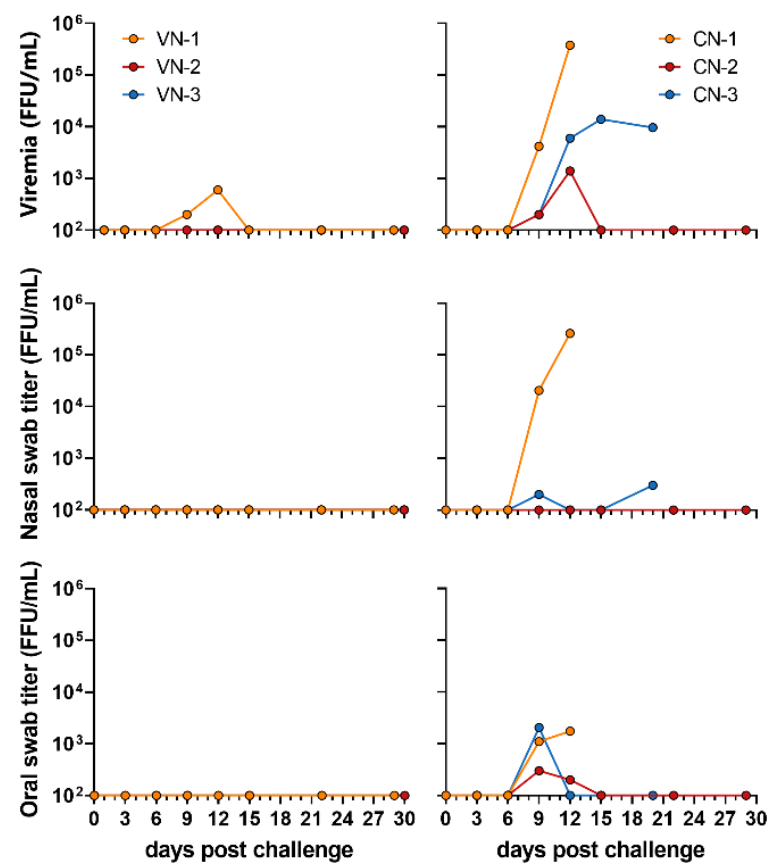

D
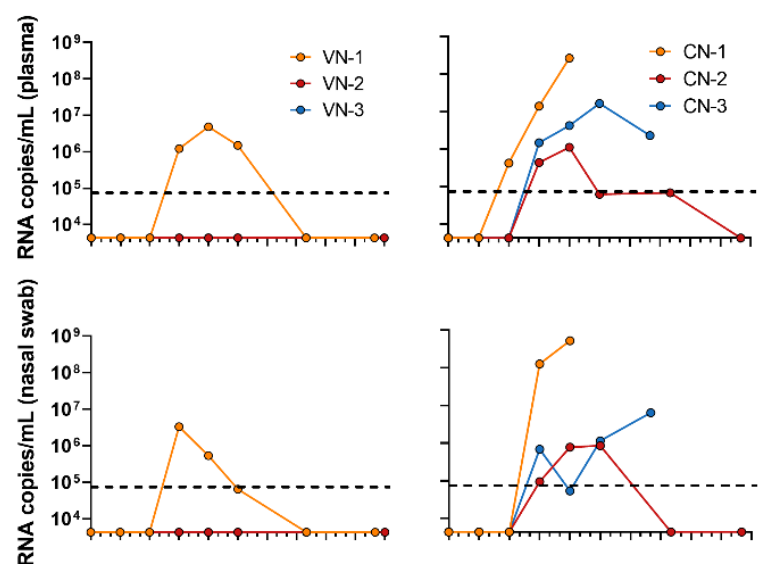
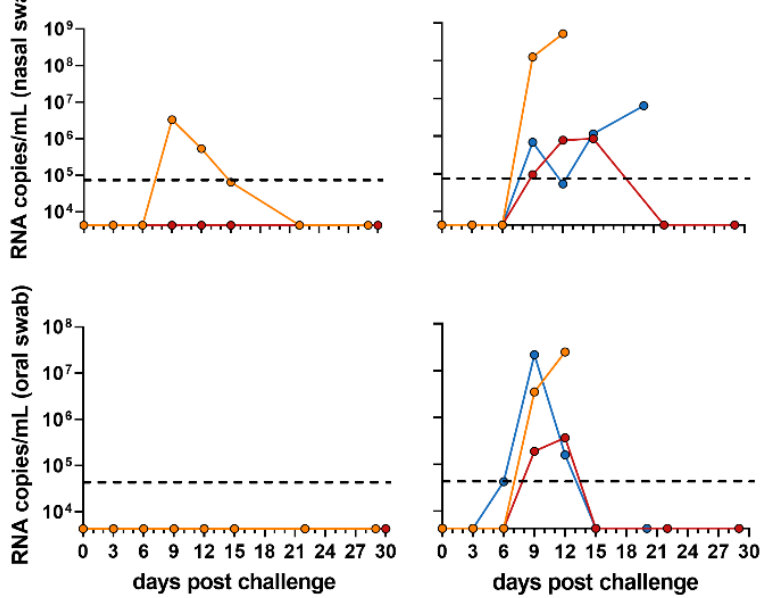

Fig. S2. LASV replication in cynomolgus monkeys infected with the heterologous lineages.

(A and B) Quantification (in focus-forming units (FFU) per milliliter $(\mathrm{mL})$ ) of LASV infectious particles in plasma (top), nasal swabs (middle), or oral swabs (bottom) according to the time after challenge in animals infected with LASV lineage VII (A) or LASV lineage II (B) in the cross-protection 
experiment. (C and D) Quantification of viral load by quantitative reverse transcription polymerase chain reaction (qRT-PCR) in the plasma (top), nasal swabs (middle), or oral swabs (bottom) according to the time after challenge in animals infected with LAV lineage VII (C) or LASV lineage II (D). Limits of detection: $100 \mathrm{FFU}$ for panels $\mathrm{A}$ and B, 4,284 copies per $\mathrm{mL}$ for panel C, 42,840 copies per $\mathrm{mL}$ for panel $\mathrm{D}$ as indicated by the dashed lines. 
A
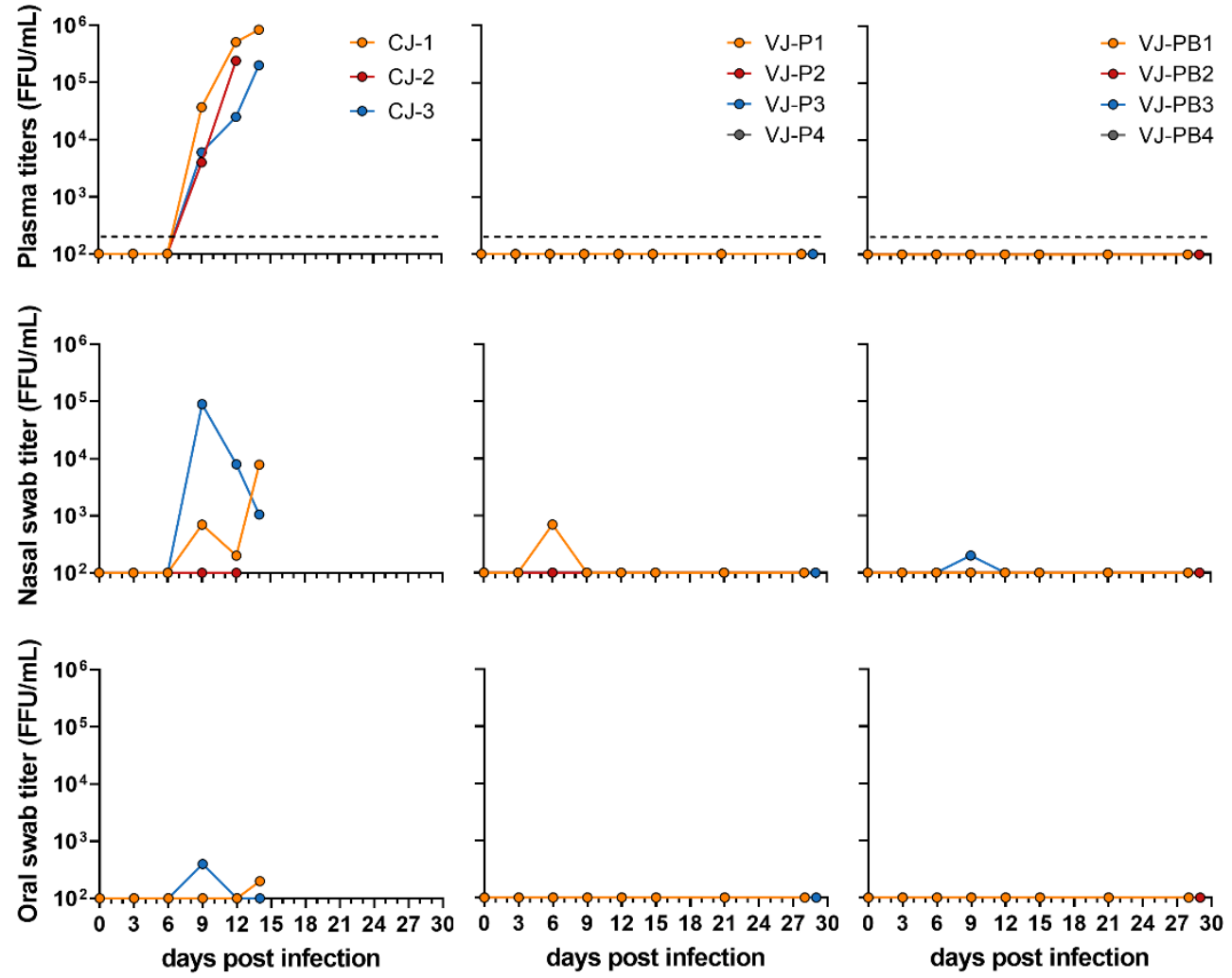

B

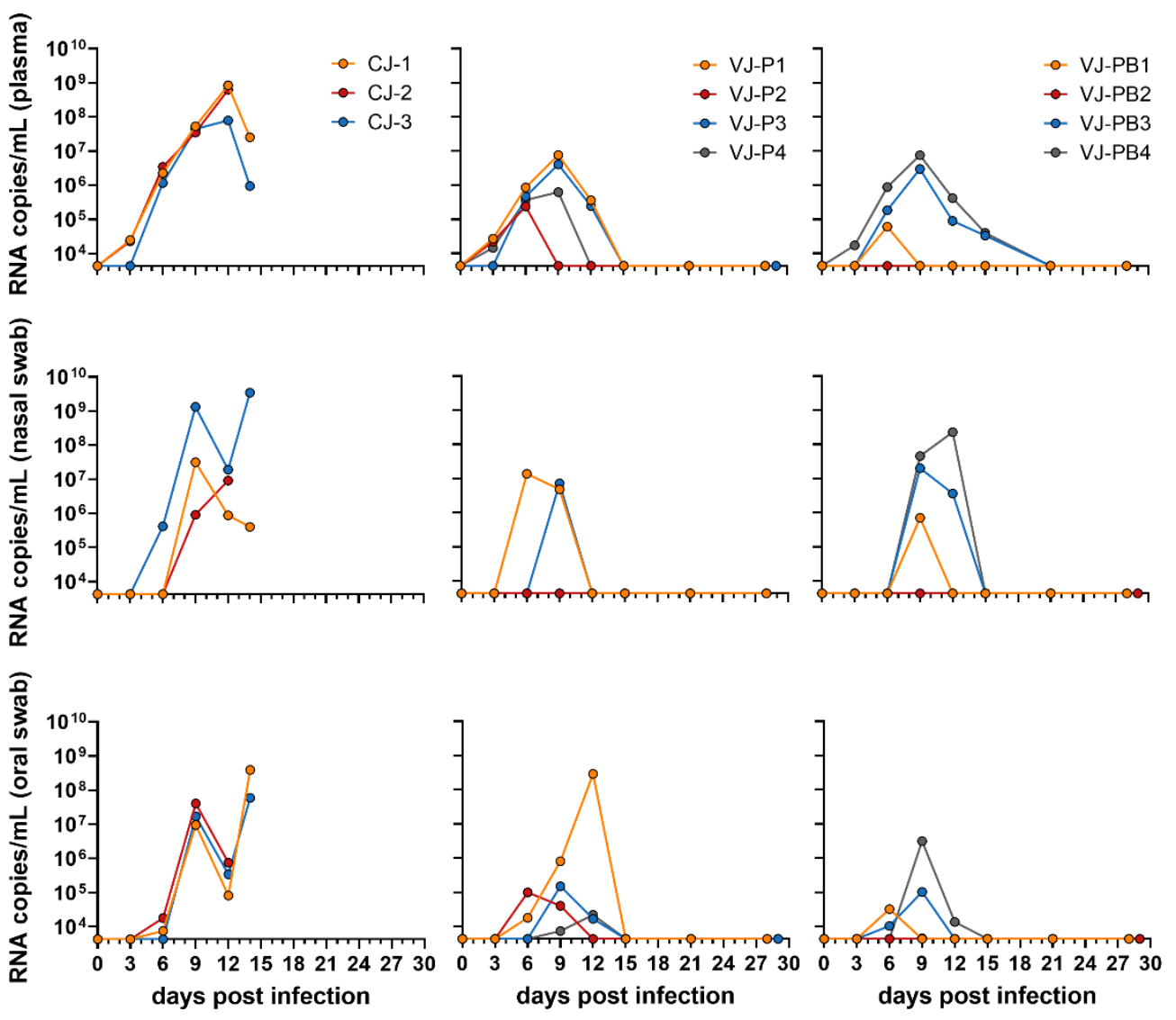


Fig. S3. LASV replication in cynomolgus monkeys infected with the homologous lineage. (A) Quantification (in FFU per milliliter) of LASV infectious particles in plasma (top), nasal swabs (middle), or oral swabs (bottom) according to the time after challenge in the long-term protection experiment. Limits of detection: $200 \mathrm{FFU}$ in plasma samples, $100 \mathrm{FFU}$ per $\mathrm{mL}$ in swab samples. (B) Quantification of viral load by RT-qPCR in the plasma (top), nasal swabs (middle), or oral swabs (bottom) according to the time after challenge. Limit of detection: 4,284 copies per mL. 


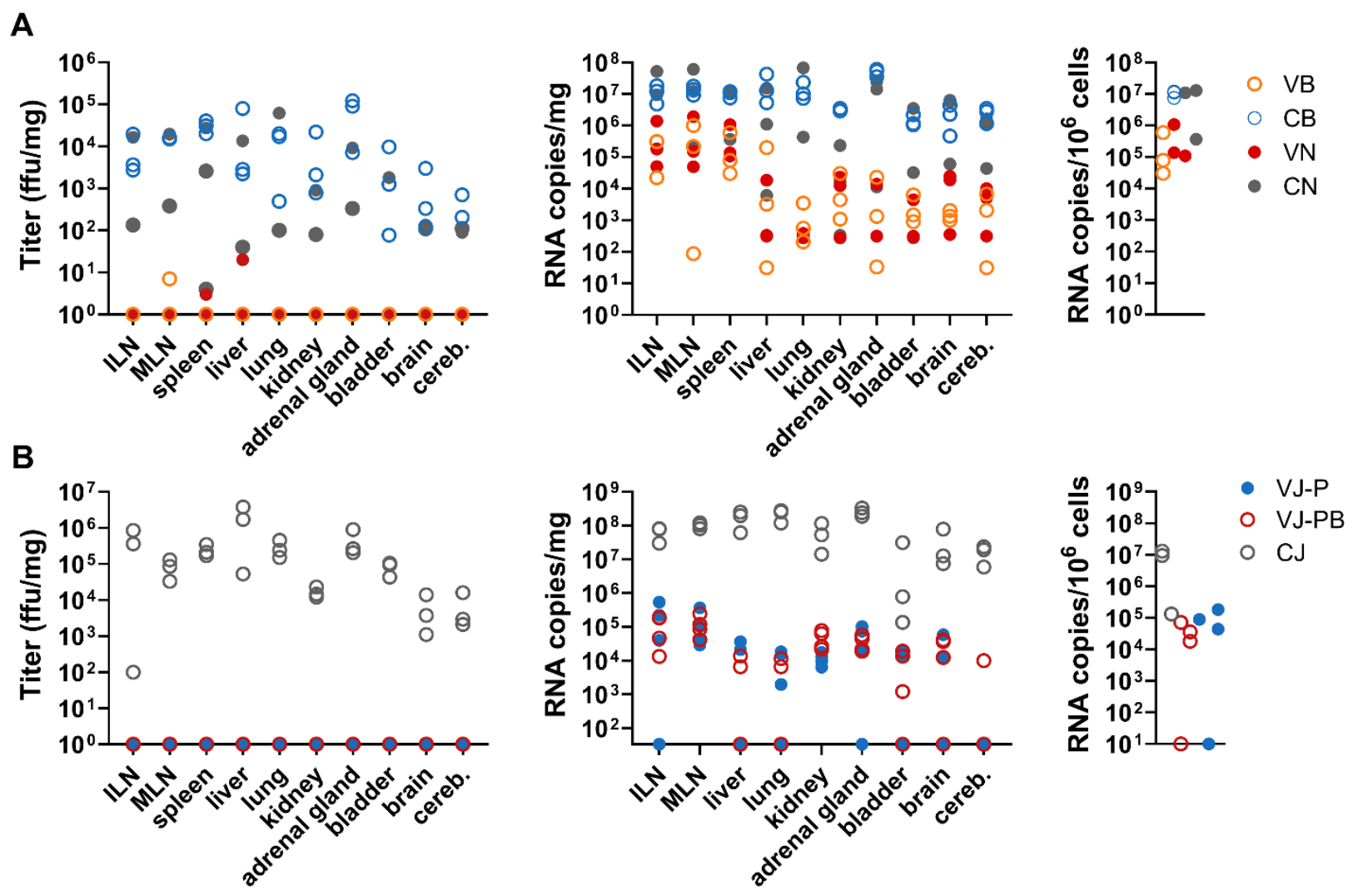

Fig. S4. LASV replication in the organs of cynomolgus monkeys after LASV challenge. (A)

Quantification (in FFU per milliliter, left) of LASV infectious particles and viral loads (in RNA copies per $\mathrm{mL}$, center) in the inguinal lymph nodes (ILN), mesenteric lymph nodes (MLN), spleen, liver, lung, kidney, adrenal glands, bladder, brain, and cerebellum (cereb.) of $\mathrm{VB}, \mathrm{CB}, \mathrm{VN}$, and $\mathrm{CN}$ animals, as well in the cells isolated from the spleen (in RNA copies per million cells, right) in the crossprotection experiment. (B) Quantification (in FFU per milliliter, left) of LASV infectious particles and viral loads (in RNA copies per $\mathrm{mL}$, center) in the inguinal lymph nodes (ILN), mesenteric lymph nodes (MLN), spleen, liver, lung, kidney, adrenal glands, bladder, brain, and cerebellum (cereb.) of VJ-P, VJ-PB and CJ animals, as well in the cells isolated from the spleen (in RNA copies per million cells, right) in the long-term protection experiment. 
A
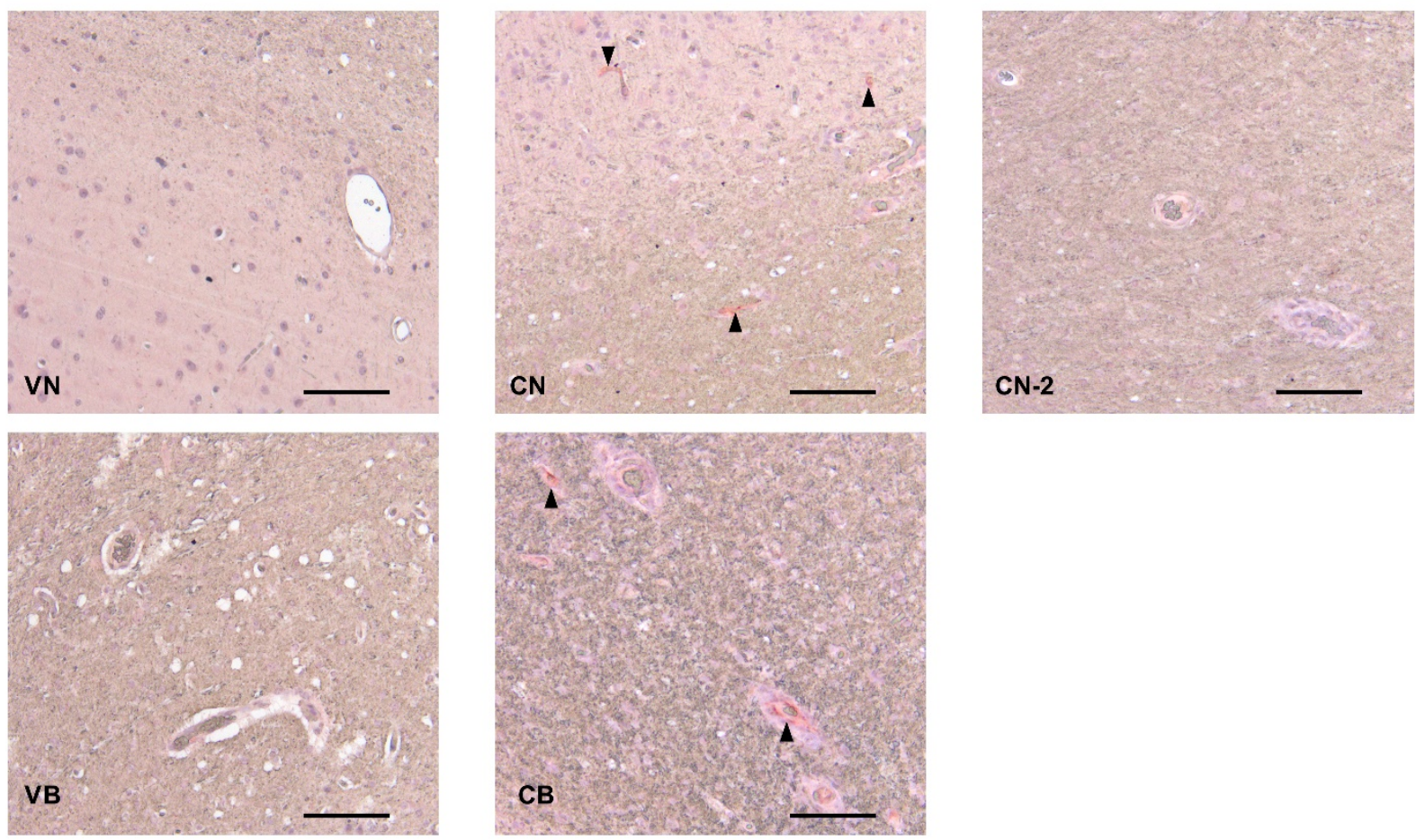

B
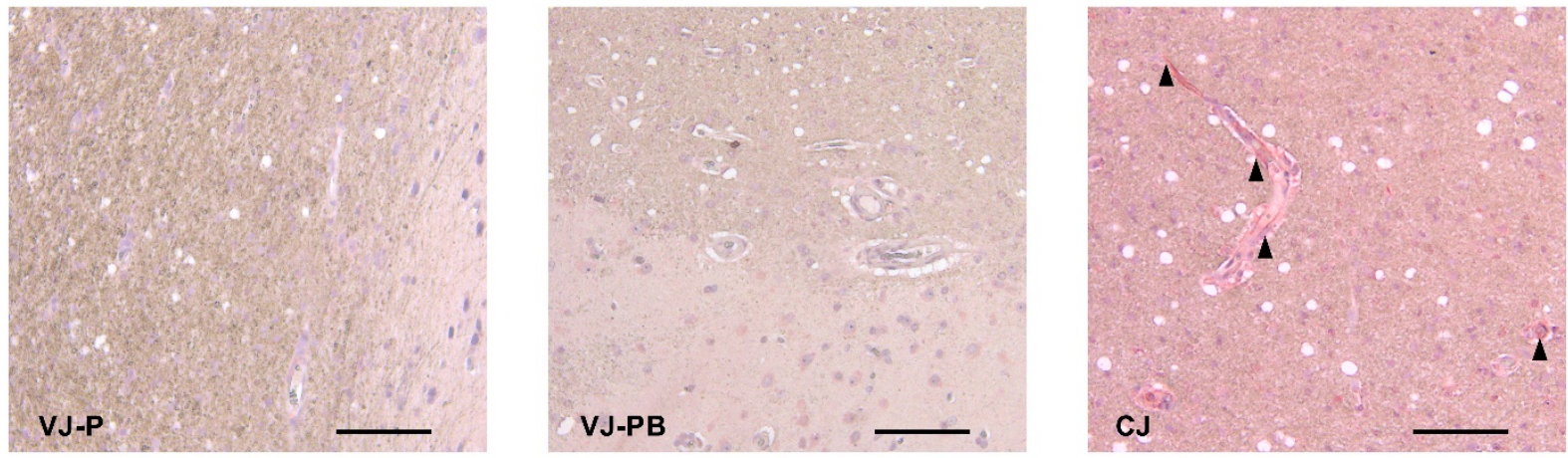

Fig. S5. LASV antigen is detected in the brains of control, but not of vaccinated, macaques.

(A and B) LASV-GP (red) immunohistochemistry in the brain of vaccinated and control animals challenged with the heterologous lineages during the cross-protection experiment $(\mathbf{A})$ or with the homologous lineage during the long-term protection experiment (B). The selected images are representative of each group of macaques, except for control animal $\mathrm{CN}-2$, who survived infection and did not present with any LASV-GP staining in the brain. Black arrowheads indicate antigenpositive cells. Scale bars: $100 \mu \mathrm{m}$. 


\begin{tabular}{|c|c|c|c|c|c|c|c|}
\hline & DPI & VB-1 & VB-2 & VB-3 & $\mathrm{VN}-1$ & $\mathrm{VN}-2$ & VN-3 \\
\hline \multirow[t]{5}{*}{ Plasma } & 2 & $\mathrm{Neg}$ & $\mathrm{Neg}$ & $\mathrm{Neg}$ & $\mathrm{Neg}$ & $\mathrm{Neg}$ & $\mathrm{Neg}$ \\
\hline & 4 & $\mathrm{Neg}$ & Neg & Neg & Neg & Neg & Neg \\
\hline & 7 & $\mathrm{Neg}$ & Neg & $\mathrm{Neg}$ & Neg & Neg & Neg \\
\hline & 14 & Neg & $\mathrm{Neg}$ & $\mathrm{Neg}$ & $\mathrm{Neg}$ & Neg & $\mathrm{Neg}$ \\
\hline & 21 & $\mathrm{Neg}$ & $\mathrm{Neg}$ & $\mathrm{Neg}$ & Neg & Neg & $\mathrm{Neg}$ \\
\hline \multirow[t]{5}{*}{ PBMC } & 2 & $\mathrm{Neg}$ & $\mathrm{Neg}$ & $\mathrm{Neg}$ & $\mathrm{Neg}$ & Neg & $\mathrm{Neg}$ \\
\hline & 4 & $\mathrm{Neg}$ & $\mathrm{Neg}$ & Neg & $\mathrm{Neg}$ & Neg & $\mathrm{Neg}$ \\
\hline & 7 & $\mathrm{Neg}$ & $\mathrm{Neg}$ & $\mathrm{Neg}$ & $\mathrm{Neg}$ & Neg & $\mathrm{Neg}$ \\
\hline & 14 & Neg & Neg & Neg & Neg & Neg & Neg \\
\hline & 21 & Neg & Neg & Neg & Neg & Neg & Neg \\
\hline \multirow[t]{7}{*}{ O.S. } & 2 & Neg & Neg & Neg & $\mathrm{Neg}$ & Neg & Neg \\
\hline & 4 & Neg & Neg & Neg & $\mathrm{Neg}$ & $\mathrm{Neg}$ & $\mathrm{Neg}$ \\
\hline & 7 & Neg & Neg & Neg & $\mathrm{Neg}$ & Neg & Neg \\
\hline & 14 & $\mathrm{Neg}$ & $\mathrm{Neg}$ & $\mathrm{Neg}$ & Neg & Neg & $\mathrm{Neg}$ \\
\hline & 21 & $\mathrm{Neg}$ & $\mathrm{Neg}$ & $\mathrm{Neg}$ & $\mathrm{Neg}$ & Neg & Neg \\
\hline & 14 & $\mathrm{Neg}$ & $\mathrm{Neg}$ & Neg & $\mathrm{Neg}$ & $\mathrm{Neg}$ & $\mathrm{Neg}$ \\
\hline & 23 & $\mathrm{Neg}$ & $\mathrm{Neg}$ & $\mathrm{Neg}$ & $\mathrm{Neg}$ & Neg & $\mathrm{Neg}$ \\
\hline \multirow[t]{7}{*}{ N.S. } & 2 & Neg & Neg & Neg & $\mathrm{Neg}$ & Neg & Neg \\
\hline & 4 & $\mathrm{Neg}$ & $\mathrm{Neg}$ & $\mathrm{Neg}$ & $\mathrm{Neg}$ & Neg & $\mathrm{Neg}$ \\
\hline & 7 & $\mathrm{Neg}$ & Neg & $\mathrm{Neg}$ & $\mathrm{Neg}$ & Neg & $\mathrm{Neg}$ \\
\hline & 14 & $\mathrm{Neg}$ & $\mathrm{Neg}$ & Neg & $\mathrm{Neg}$ & Neg & Neg \\
\hline & 21 & Neg & Neg & $\mathrm{Neg}$ & $\mathrm{Neg}$ & Neg & Neg \\
\hline & 14 & $\mathrm{Neg}$ & $\mathrm{Neg}$ & $\mathrm{Neg}$ & Neg & $\mathrm{Neg}$ & $\mathrm{Neg}$ \\
\hline & 23 & Neg & Neg & $\mathrm{Neg}$ & $\mathrm{Neg}$ & $\mathrm{Neg}$ & Neg \\
\hline \multirow[t]{5}{*}{ Urine } & 2 & $\mathrm{Neg}$ & $\mathrm{Neg}$ & Neg & $\mathrm{Neg}$ & Neg & $\mathrm{Neg}$ \\
\hline & 4 & $\mathrm{Neg}$ & $\mathrm{Neg}$ & $\mathrm{Neg}$ & $\mathrm{Neg}$ & $\mathrm{Neg}$ & $\mathrm{Neg}$ \\
\hline & 7 & $\mathrm{Neg}$ & $\mathrm{Neg}$ & $\mathrm{Neg}$ & $\mathrm{Neg}$ & Neg & $\mathrm{Neg}$ \\
\hline & 14 & $\mathrm{Neg}$ & $\mathrm{Neg}$ & Neg & $\mathrm{Neg}$ & $\mathrm{Neg}$ & $\mathrm{Neg}$ \\
\hline & 21 & Neg & $\mathrm{Neg}$ & $\mathrm{Neg}$ & $\mathrm{Neg}$ & $\mathrm{Neg}$ & $\mathrm{Neg}$ \\
\hline
\end{tabular}

Table S1. Detection of vaccine RNA by RT-PCR for the cross-protection experiment. DPI, days post infection; PBMC, peripheral blood mononuclear cells; O.S., oral swab; N.S., nasal swab; Neg, negative; NT, not tested. 


\begin{tabular}{|c|c|c|c|c|c|c|c|c|c|}
\hline & DPI & VJ-P1 & VJ-P2 & VJ-P3 & VJ-P4 & VJ-PB1 & VJPB-2 & VJ-PB3 & VJ-PB4 \\
\hline \multirow[t]{8}{*}{ Plasma } & 2 & Neg & Neg & Neg & Neg & Neg & Neg & Neg & Neg \\
\hline & 4 & $\mathrm{Neg}$ & $\mathrm{Neg}$ & $\mathrm{Neg}$ & $\mathrm{Neg}$ & $\mathrm{Neg}$ & $\mathrm{Neg}$ & $\mathrm{Neg}$ & $\mathrm{Neg}$ \\
\hline & 7 & $\mathrm{Neg}$ & $\mathrm{Neg}$ & $\mathrm{Neg}$ & $\mathrm{Neg}$ & $\mathrm{Neg}$ & $\mathrm{Neg}$ & $\mathrm{Neg}$ & $\mathrm{Neg}$ \\
\hline & 37 & NT & NT & NT & NT & $\mathrm{Neg}$ & $\mathrm{Neg}$ & $\mathrm{Neg}$ & $\mathrm{Neg}$ \\
\hline & 39 & NT & NT & NT & NT & $\mathrm{Neg}$ & $\mathrm{Neg}$ & $\mathrm{Neg}$ & $\mathrm{Neg}$ \\
\hline & 44 & $\mathrm{Neg}$ & $\mathrm{Neg}$ & $\mathrm{Neg}$ & $\mathrm{Neg}$ & NT & NT & NT & NT \\
\hline & 46 & NT & NT & NT & NT & $\mathrm{Neg}$ & $\mathrm{Neg}$ & $\mathrm{Neg}$ & $\mathrm{Neg}$ \\
\hline & 58 & NT & NT & NT & NT & $\mathrm{Neg}$ & $\mathrm{Neg}$ & $\mathrm{Neg}$ & $\mathrm{Neg}$ \\
\hline \multirow[t]{8}{*}{ PBMC } & 2 & $\mathrm{Neg}$ & $\mathrm{Neg}$ & $\mathrm{Neg}$ & $\mathrm{Neg}$ & $\mathrm{Neg}$ & $\mathrm{Neg}$ & $\mathrm{Neg}$ & $\mathrm{Neg}$ \\
\hline & 4 & Neg & $\mathrm{Neg}$ & Neg & Neg & $\mathrm{Neg}$ & $\mathrm{Neg}$ & $\mathrm{Neg}$ & $\mathrm{Neg}$ \\
\hline & 7 & Neg & Neg & Neg & $\mathrm{Neg}$ & Neg & $\mathrm{Neg}$ & $\mathrm{Neg}$ & Neg \\
\hline & 37 & NT & NT & NT & NT & $\mathrm{Neg}$ & $\mathrm{Neg}$ & $\mathrm{Neg}$ & $\mathrm{Neg}$ \\
\hline & 39 & NT & NT & NT & NT & $\mathrm{Neg}$ & $\mathrm{Neg}$ & $\mathrm{Neg}$ & $\mathrm{Neg}$ \\
\hline & 44 & $\mathrm{Neg}$ & $\mathrm{Neg}$ & Neg & $\mathrm{Neg}$ & NT & NT & NT & NT \\
\hline & 46 & NT & NT & NT & NT & $\mathrm{Neg}$ & Neg & $\mathrm{Neg}$ & Neg \\
\hline & 58 & NT & NT & NT & NT & $\mathrm{Neg}$ & $\mathrm{Neg}$ & $\mathrm{Neg}$ & $\mathrm{Neg}$ \\
\hline \multirow[t]{8}{*}{ O.S. } & 2 & $\mathrm{Neg}$ & $\mathrm{Neg}$ & $\mathrm{Neg}$ & $\mathrm{Neg}$ & $\mathrm{Neg}$ & $\mathrm{Neg}$ & $\mathrm{Neg}$ & $\mathrm{Neg}$ \\
\hline & 4 & $\mathrm{Neg}$ & $\mathrm{Neg}$ & $\mathrm{Neg}$ & Neg & $\mathrm{Neg}$ & $\mathrm{Neg}$ & $\mathrm{Neg}$ & $\mathrm{Neg}$ \\
\hline & 7 & $\mathrm{Neg}$ & $\mathrm{Neg}$ & Neg & Neg & $\mathrm{Neg}$ & Neg & $\mathrm{Neg}$ & Neg \\
\hline & 37 & NT & NT & NT & NT & $\mathrm{Neg}$ & $\mathrm{Neg}$ & $\mathrm{Neg}$ & $\mathrm{Neg}$ \\
\hline & 39 & NT & NT & NT & NT & $\mathrm{Neg}$ & $\mathrm{Neg}$ & $\mathrm{Neg}$ & $\mathrm{Neg}$ \\
\hline & 44 & $\mathrm{Neg}$ & $\mathrm{Neg}$ & $\mathrm{Neg}$ & $\mathrm{Neg}$ & NT & NT & NT & NT \\
\hline & 46 & NT & NT & NT & NT & $\mathrm{Neg}$ & $\mathrm{Neg}$ & $\mathrm{Neg}$ & $\mathrm{Neg}$ \\
\hline & 58 & NT & NT & NT & NT & $\mathrm{Neg}$ & $\mathrm{Neg}$ & $\mathrm{Neg}$ & Neg \\
\hline \multirow[t]{8}{*}{ N.S. } & 2 & $\mathrm{Neg}$ & $\mathrm{Neg}$ & $\mathrm{Neg}$ & $\mathrm{Neg}$ & $\mathrm{Neg}$ & $\mathrm{Neg}$ & $\mathrm{Neg}$ & $\mathrm{Neg}$ \\
\hline & 4 & Neg & $\mathrm{Neg}$ & Neg & Neg & $\mathrm{Neg}$ & $\mathrm{Neg}$ & $\mathrm{Neg}$ & $\mathrm{Neg}$ \\
\hline & 7 & $\mathrm{Neg}$ & Neg & $\mathrm{Neg}$ & $\mathrm{Neg}$ & $\mathrm{Neg}$ & $\mathrm{Neg}$ & $\mathrm{Neg}$ & $\mathrm{Neg}$ \\
\hline & 37 & NT & NT & NT & NT & $\mathrm{Neg}$ & $\mathrm{Neg}$ & $\mathrm{Neg}$ & $\mathrm{Neg}$ \\
\hline & 39 & NT & NT & NT & NT & $\mathrm{Neg}$ & $\mathrm{Neg}$ & $\mathrm{Neg}$ & $\mathrm{Neg}$ \\
\hline & 44 & $\mathrm{Neg}$ & $\mathrm{Neg}$ & $\mathrm{Neg}$ & $\mathrm{Neg}$ & NT & NT & NT & NT \\
\hline & 46 & NT & NT & NT & NT & $\mathrm{Neg}$ & $\mathrm{Neg}$ & $\mathrm{Neg}$ & $\mathrm{Neg}$ \\
\hline & 58 & NT & NT & NT & NT & $\mathrm{Neg}$ & $\mathrm{Neg}$ & $\mathrm{Neg}$ & $\mathrm{Neg}$ \\
\hline \multirow[t]{8}{*}{ Urine } & 2 & $\mathrm{Neg}$ & $\mathrm{Neg}$ & $\mathrm{Neg}$ & $\mathrm{Neg}$ & $\mathrm{Neg}$ & $\mathrm{Neg}$ & $\mathrm{Neg}$ & Neg \\
\hline & 4 & $\mathrm{Neg}$ & $\mathrm{Neg}$ & $\mathrm{Neg}$ & $\mathrm{Neg}$ & $\mathrm{Neg}$ & $\mathrm{Neg}$ & $\mathrm{Neg}$ & $\mathrm{Neg}$ \\
\hline & 7 & $\mathrm{Neg}$ & $\mathrm{Neg}$ & $\mathrm{Neg}$ & $\mathrm{Neg}$ & $\mathrm{Neg}$ & $\mathrm{Neg}$ & $\mathrm{Neg}$ & $\mathrm{Neg}$ \\
\hline & 37 & NT & NT & NT & NT & Neg & $\mathrm{Neg}$ & $\mathrm{Neg}$ & Neg \\
\hline & 39 & NT & NT & NT & NT & $\mathrm{Neg}$ & $\mathrm{Neg}$ & $\mathrm{Neg}$ & Neg \\
\hline & 44 & $\mathrm{Neg}$ & $\mathrm{Neg}$ & $\mathrm{Neg}$ & $\mathrm{Neg}$ & NT & NT & NT & NT \\
\hline & 46 & NT & NT & NT & NT & $\mathrm{Neg}$ & $\mathrm{Neg}$ & $\mathrm{Neg}$ & $\mathrm{Neg}$ \\
\hline & 58 & NT & NT & NT & NT & $\mathrm{Neg}$ & $\mathrm{Neg}$ & $\mathrm{Neg}$ & $\mathrm{Neg}$ \\
\hline
\end{tabular}

Table S2. Detection of vaccine RNA by RT-PCR for the long-term protection experiment 


\begin{tabular}{|c|c|c|c|c|c|c|}
\hline NP & Lineage I & Lineage II & Lineage III & Lineage V & Lineage VI & Lineage VII \\
\hline Lineage IV & 90.5 & 89.9 & 90.5 & 93.6 & 85.9 & 90.5 \\
\hline GPC & Lineage I & Lineage II & Lineage III & Lineage V & Lineage VI & Lineage VII \\
\hline Lineage IV & 92.8 & 93.6 & 92 & 94.9 & 91.4 & 93.4 \\
\hline
\end{tabular}

Table S3. Percentage amino acid homology between the NP and GPC proteins from strain Josiah (Clade 4) and strains representing other clades. Lineage 1: NIG_Pinneo_LP_AF181853.1; lineage 2: MT193282.1 Lassa mammarenavirus isolate BEN-16131; lineage 3: NIG_CSF_AF333969.1; lineage 4: SL_Josiah_J04324.1; lineage 5: AF246121.2 Lassa virus strain AV ; lineage 6: NIG_Kako428_KT992425.1 ; C lineage 7: MT193283.1 Lassa mammarenavirus isolate BEN-16081. 


\begin{tabular}{|c|c|c|}
\hline Temperature & & Score \\
\hline & \multirow{4}{*}{ Day $\mathrm{T}^{\circ} \mathrm{C}$} & $0 \mathrm{pt}: \Delta \mathrm{T}^{\circ} \leq \pm 1$ \\
\hline & & $1 \mathrm{pt}: 1<\Delta \mathrm{T}^{\circ} \leq 1.7$ \\
\hline & & 2 pts: $1.7<\Delta \mathrm{T}^{\circ} \leq 2.2$ \\
\hline & & 3 pts: $\Delta \mathrm{T}^{\circ}> \pm 2.2$ \\
\hline \multirow[t]{5}{*}{ Weight loss } & & Score \\
\hline & \multirow{4}{*}{$\begin{array}{l}\text { Day weight } \\
(\mathrm{kg})\end{array}$} & $0 \mathrm{pt}: \Delta \mathrm{W} \leq 5.4 \%$ \\
\hline & & $1 \mathrm{pt}: 5.4 \%<\Delta \mathrm{W} \leq 7.5 \%$ \\
\hline & & 2 pts: $7.5 \%<\Delta W \leq 10 \%$ \\
\hline & & 3 pts: $\Delta 10>10 \%$ \\
\hline \multirow[t]{3}{*}{ Bleeding } & & Score \\
\hline & & 0 pt: nothing remarkable (NR) \\
\hline & & 3 pts: bleeding \\
\hline \multirow[t]{5}{*}{ Petechiae } & & Score \\
\hline & \multirow{4}{*}{ Petechiae \% of body } & $0 \mathrm{pt}: \mathrm{NR}$ \\
\hline & & $1 \mathrm{pt}: 1 \%$ to $19 \%$ \\
\hline & & 2 pts: $20 \%$ to $49 \%$ \\
\hline & & 3 pts: $>50 \%$ \\
\hline \multirow[t]{5}{*}{ Stool } & & Score \\
\hline & & 0 pt: NR \\
\hline & & 1 pt: loose stool \\
\hline & & 2 pts : diarrhea \\
\hline & & 3 pts: mucous and fibrinous diarrhea \\
\hline \multirow[t]{6}{*}{ Responsiveness } & & Score \\
\hline & & 0 pt: normal activity \\
\hline & & 2 pts: general loss in tone, sightly slow in motion \\
\hline & & $\begin{array}{l}4 \text { pts: more often seated than perched, still interacts } \\
\text { with its environment }\end{array}$ \\
\hline & & $\begin{array}{l}6 \text { pts: weak, stays seated and seeks isolation. } \\
\text { Decreased interactions with its environment. } \\
\text { Difficulty moving and reflexes reduced. }\end{array}$ \\
\hline & & $\begin{array}{l}10 \text { pts: prostration and no more interaction with the } \\
\text { environment. }\end{array}$ \\
\hline \multirow[t]{3}{*}{ Dehydration } & & Score \\
\hline & & 0 pt: NR \\
\hline & & 1 pt: dehydration \\
\hline TOTAL SCORE & & Euthanasia if total score $\geq 15^{*}$ \\
\hline
\end{tabular}


Table S4. Scoring and endpoints for animal studies. Euthanasia was also performed when an animal reached one of the following endpoints: strong prostration, body temperature below 35.8 ${ }^{\circ} \mathrm{C}$, no awakening at 150 minutes post anesthesia, or if the animal was moribund. 